\title{
THE PHYSICAL OCEANOGRAPHY OF THE BRAS D'OR LAKES
}

\author{
BRIAN PETRIE ${ }^{1}$ and GARY BUGDEN \\ Ocean Sciences Division \\ Department of Fisheries and Oceans \\ Bedford Institute of Oceanography \\ P. O. Box 1006, Dartmouth, N. S. , Canada B2Y 4 A2
}

\begin{abstract}
In the Bras d'Or Lakes the mean water circulation for the spring to fall seasons consists of a surface flow towards the ocean and a subsurface flow into the Lakes. The outflow from the Lakes is about $1100 \mathrm{~m}^{3} \mathrm{~s}^{-1}$. Vertical exchanges and flushing times throughout the Lakes and their effects on oxygen distribution are discussed. Currents at some locations in the Lakes are frequently so weak that they cannot turn the rotors of conventional current meters; at other sites, they can be so strong that they rival flows in the Bay of Fundy. Of note are observations from Barra Strait and the Great Bras d'Or Channel that feature maximum flows of about 1 and $3 \mathrm{~m} \mathrm{~s}^{-1}$, dominated by strong semi-diurnal tidal currents. Temperature and salinity change markedly from Sydney Bight into the Lakes and vertically within the Lakes. Sea level variations caused by tides decrease rapidly from the entrance to the Lakes along the Great Bras d'Or Channel. On the other hand, low frequency fluctuations are only slightly attenuated. Surface wave data from the North Basin and Bras d'Or Lake compare reasonably well with equations that relate wind speed and fetch to significant wave height. The long-term mean ice cover for the Lakes is derived from 30 years of data. Below (above) normal winter air temperatures are related to above (below) normal ice cover.
\end{abstract}

Dans les lacs Bras d'Or, la circulation moyenne de l'eau du printemps à l'automne consiste en un écoulement de surface en direction de l'océan et un écoulement en profondeur vers l'intérieur des lacs. Le débit sortant du lac est d'environ $1100 \mathrm{~m}^{3} \mathrm{~s}^{-1}$. On discute ici des échanges verticaux et du temps de renouvellement des eaux du lac, ainsi que de leurs effets sur la distribution d'oxygène. En certains endroits du lac, les courants sont souvent si faibles qu'ils n'actionnent pas les rotors des courantomètres; en d'autres endroits, ils peuvent être si forts qu'ils rivalisent avec ceux de la baie de Fundy. À noter que des observations en provenance du détroit de Barra et du chenal Great Bras d'Or indiquent des courants maximaux d'environ 1 et $3 \mathrm{~m} \mathrm{~s}^{-1}$, dominés par de forts courants de marée semidiurne. La température et la salinité changent nettement entre la baie de Sydney et les lacs, ainsi que verticalement au sein de ces derniers. Les variations du niveau de la mer dues aux marées diminuent rapidement à partir de l'entrée des lacs le long du chenal Great Bras d'Or, mais les fluctuations de basse fréquence sont quant à elles à peine atténuées. Les données de vagues dans le bassin North et les lacs Bras d'Or montrent une comparaison assez bonne avec la relation théorique entre la vitesse du vent, la portée du vent et la hauteur significative des vagues. La couverture de glace moyenne à long terme est calculée à partir de trente ans de données. Les températures hivernales de l'air inférieures (supérieures) à la normale sont associées à une couverture de glace supérieure (inférieure) à la normale.

\section{Introduction}

The Bras d'Or Lakes are connected to Sydney Bight and the Atlantic Ocean by a 30 km long, narrow, shallow passage, the Great Bras d'Or Channel (Fig 1). The channel has an average width of about $1.3 \mathrm{~km}$, an average depth of about $19.5 \mathrm{~m}$ and a maximum depth of $95 \mathrm{~m}$. The most severe restriction is at the mouth of the channel where it opens onto Sydney Bight. There the width is only $320 \mathrm{~m}$, the maximum depth is $16.2 \mathrm{~m}$, and the cross-sectional area is $2400 \mathrm{~m}^{2}$. It is through this small opening that most of the water exchange between the Lakes and the ocean must occur.

The $8 \mathrm{~km}$ long Little Bras d'Or Channel, the only other permanently open connection to the ocean, is even more restrictive. It is less than $100 \mathrm{~m}$ wide and $5 \mathrm{~m}$ deep on average. It does not appear to play a major role in the temperature and salinity

\footnotetext{
Author to whom correspondence should be addressed
} 


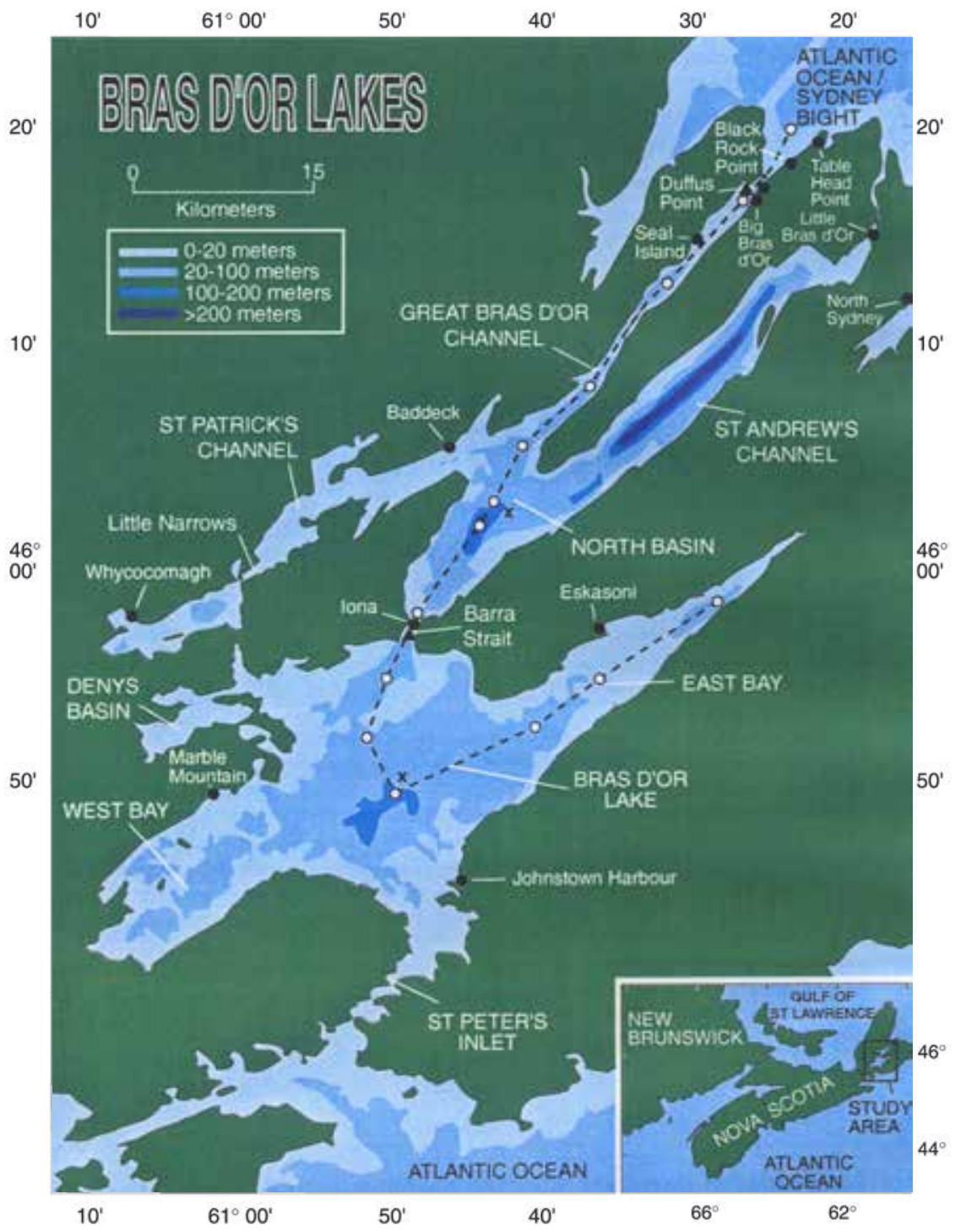

Fig 1 Map of the Bras d'Or Lakes with place names used in the text. Sites of tide gauges (solid dot), moorings measuring current, temperature and salinity (solid triangle), wave rider buoys ( $\mathrm{x}$ ) and ship-based temperature and salinity stations (open dot, dashed line) are shown. 
distributions in the Lakes (Gurbutt and Petrie, 1995). A lock on St. Peter's Inlet on the southern side of Bras d'Or Lake is opened occasionally to allow vessels to enter or leave the Lakes. Before the St. Peter's Canal was completed in 1869 after 15 years of digging, blasting and drilling, ships were hauled across the isthmus to the Lakes on skids. The major obstacle encountered during the construction was a solid granite hill 20 m high (Parks Canada, 2001).

The interior of the Lakes consists of several interconnected basins and channels with a maximum depth of $280 \mathrm{~m}$ in St. Andrew's Channel. Two passages of note are Barra Strait which controls the exchange between the North Basin and Bras d'Or Lake, and Little Narrows which separates Whycocomagh Bay from St. Patrick's Channel. The Lakes have a shoreline of about $1000 \mathrm{~km}$ excluding islands (from 1:50 000 digital charts), total surface area of about 1.07 billion $\mathrm{m}^{2}$, and a volume of approximately 32 billion $\mathrm{m}^{3}$.

The restricted exchange with the Atlantic Ocean, freshwater inflow, and the exchange of heat between the atmosphere and the water are major factors influencing the circulation, temperature and salinity of the Bras d'Or Lakes.

The physical oceanography of the Lakes involves the circulation, both the average currents and the fluctuating currents caused by tides, wind and freshwater inflow, the distribution of temperature, salinity and density, the variations of sea level, mixing within the Lakes, surface waves and ice cover. These processes also affect other variables including the distribution of nutrients and dissolved oxygen in the water, the movement of sediments, the dispersion of pollutants and consequently water quality, and coastal erosion. A knowledge and understanding of these physical processes are fundamental to responsible and effective management of the Lakes.

In the following sections, we present brief discussions of the mean circulation of the Lakes, mixing processes and upwelling, flushing times for the separate basins of the Lakes, the distribution of temperature and salinity, tidal and non-tidal currents and sea level changes, surface waves and ice cover.

\section{Mean Circulation}

The Bedford Institute of Oceanography conducted broad scale surveys of the Lakes from 1972 to 1974, making measurements of temperature, salinity, and dissolved oxygen concentrations from ships and small boats (Krauel 1975a, b). In addition, recording instruments were moored at depths ranging from 4 to $183 \mathrm{~m}$ below the surface in the spring and summer of 1973 and 1974. These current meters measured speed and direction of water flow at 13 locations throughout the Lakes; each record was about 1 month long. Seven sites were occupied only once, 4 sites twice, and 2 sites three times. Twenty eight records were collected in 1973, 21 in 1974. Sea level recorders were also placed at 9 shore locations at the same time.

These data were used by Gurbutt and Petrie (1995) to derive a picture of the mean water circulation in the Lakes for the spring, summer and fall seasons. There were too few data from the winter to extend the circulation into that season. Moreover, during the winter, the Lakes are frequently covered completely by ice, a condition that could profoundly affect the circulation by cutting off direct contact with atmospheric forcing. The circulation in the upper (0-10 m) and lower (10-50 m or bottom if less than $50 \mathrm{~m}$ ) layers of the Lakes are shown schematically in Fig 2A, B. The thickness of the lines depicting the currents is proportional to the amount of water transported. The thicker the line the greater the quantity of water moving, and vice versa. 


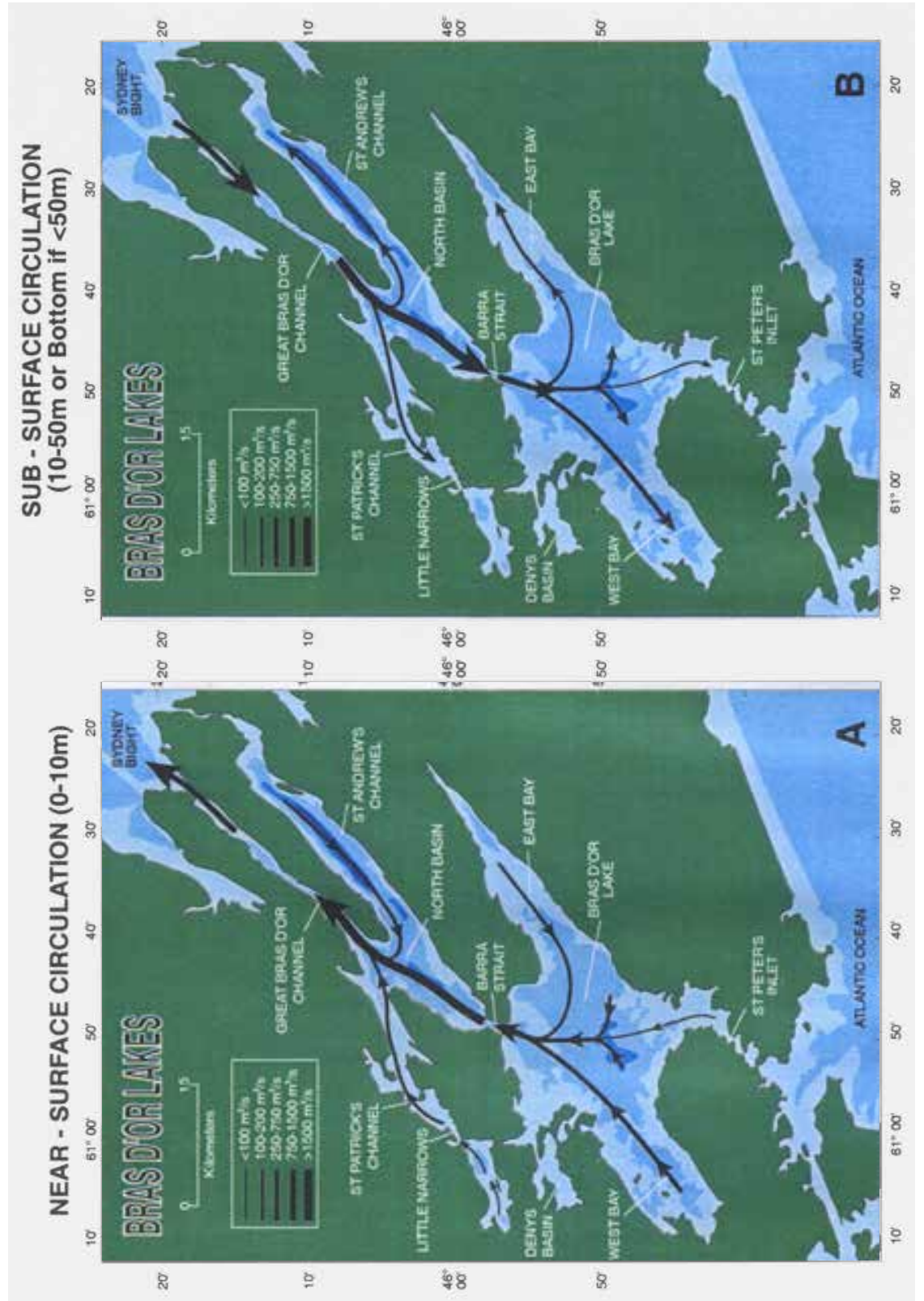

Fig 2A Map of the near-surface circulation in the Bras d'Or Lakes. The thickness of the line is proportional to the strength of the flow. (B) Map of the sub-surface (approximately 10-50 m) circulation in the Bras d'Or Lakes. The thickness of the line is proportional to the strength of the flow. 
Beginning in the southwestern region of the Lakes, the surface layer flows from West and East Bays, the former about 3 times stronger than the latter, and joins the currents in Bras d'Or Lake to form a strong flow through Barra Strait into the North Basin. This flow then combines with weaker flows from St. Andrew's and St. Patrick's Channels to form a near-surface current through the Great Bras d'Or Channel that discharges into Sydney Bight (Fig 2A). The surface circulation carries the freshwater runoff from the Lakes into the ocean.

The sub-surface circulation is almost a carbon copy of the near-surface flow but in the opposite direction (Fig 2B). In the Great Bras d'Or Channel, the sub-surface current moves from Sydney Bight into the North Basin, St. Andrew's and St. Patrick's Channels. The current in North Basin flows through Barra Strait into Bras d'Or Lake and then into West and East Bays. The sub-surface flows carry relatively salty water from Sydney Bight into the Lakes.

The circulation shown in Fig 2A, B must conserve mass; i.e., for each layer in each area of the Lakes, the mass of water entering a layer must equal the mass of water leaving. The flows can be either horizontal, from one area to an adjacent area, or vertical, from one layer to another within the same region of the Lakes. Carried to an extreme, if mass conservation did not hold then, over time, the Lakes would either drain completely, if more water flowed out than in, or flood the adjacent countryside, if the opposite were true. Similar conservation principles hold for salt and heat. If the amount of salt in the Lakes remains constant, the quantity entering the system must balance the amount leaving. If the total salt content in the Lakes is increasing, more must come in then leave and vice versa. The water temperatures in the Lakes depend on balances between the sources or sinks of heat; e.g., in spring and summer there is a net transfer of heat from the atmosphere to the Lakes, in winter the opposite is true. The flow from Sydney Bight generally brings colder water into the Lakes. Gurbutt and Petrie (1995) applied these conservation principles to derive the mean water circulation.

The term "estuarine" is often used to characterize the pattern of circulation just described for a semi-enclosed area that has significant freshwater inflow. Accompanying this characteristic circulation of outflow in the upper layer and inflow in an underlying layer is a distribution of surface salinity that has the freshest water within the Lakes and increasing salinity towards the ocean. The sub-surface salinity follows the same pattern.

\section{Mixing and Upwelling}

Turbulent processes mix the surface layer waters with the sub-surface waters as they flow past each other; in the case of the mean circulation in the Lakes, the layers are moving in opposite directions. The fresher and generally warmer waters of the surface layer mix into the sub-surface layer causing it to warm and become less salty. At the same time, the sub-surface waters are mixed into the surface layer making it saltier and cooler.

Mixing enhances the estuarine circulation in the Lakes. If the less dense freshwater flowing into the Lakes was not mixed with the underlying saltier waters, it would simply flow out as a thin surface layer. The discharge into the Lakes would be balanced by the outflow to the ocean. Think of the freshwater as a dye. As mixing and consequently the salinity of the upper layer increases, the freshwater is effectively diluted by the saltier waters; therefore more of this diluted mixture must flow out into the ocean in order to balance the freshwater inflow. That is, the surface component of estuarine 
circulation must strengthen. By the same token, the underlying layer has lost salt to the upper layer, which must be compensated by inflow of salty water from the ocean.

Mixing can be caused by a number of mechanisms such as wind forcing, tides and bottom friction, and estuarine-induced current shear. Any mechanism that causes one layer of water to move at a different speed or direction than an adjacent layer is capable of generating mixing. On the other hand, a process, such a freshwater inflow, that increases the density contrast between surface and sub-surface waters will tend to suppress mixing. In fact, for freshwater inflow, there is a competition between the tendency to increase the vertical density contrast which inhibits mixing and the tendency to increase the velocity differences between layers that enhances mixing.

In their model of the Lakes circulation, Gurbutt and Petrie (1995) divided the vertical currents between 2 layers into 2 components. The first component, the "exchange" has equal values in both directions, i.e., as much water is mixed from the surface to the sub-surface layer as is mixed from the sub-surface to the surface layer. The second component represented a net flow from one layer to another: upwelling if it was from the sub-surface to the surface layer, downwelling if it was in the opposite direction.

The mixing between layers varies strongly throughout the Lakes as is indicated in Fig 3A. In this diagram, we have plotted the "exchange" between the surface and sub-surface layers divided by the volume of the latter. This gives a measure of the strength of the mixing from the surface to sub-surface layer. The strongest mixing by far occurs in the Great Bras d'Or Channel, where the intensity is about 100 to 150 times greater than in Whycocomagh Bay, East Bay and St. Andrews Channel, and 10-30 times more than in St. Patrick's Channel, West Bay, North Basin and Bras d'Or Lake. The primary factor that contributes to the strong mixing in the Great Bras d'Or Channel is the current associated with the semi-diurnal lunar tide. Gurbutt and Petrie (1995) also identified Barra Strait as another area where intense mixing occurs.

The mixing between the fresher surface layer and the sub-surface layer reduces the sub-surface layer's salinity; furthermore, because the sub-surface flow is inward from the ocean, some of the freshwater is carried back into the Lakes. Mixing also brings generally highly oxygenated water from the surface to the layers below. Other water-borne materials would behave in a similar fashion.

Two areas of the Lakes, North Basin and St. Andrew's Channel, have deep, isolated basins with depths exceeding $200 \mathrm{~m}$. Gurbutt and Petrie (1995) incorporated these deep regions as distinct compartments in their model and derived the mixing rates that best fit the existing data (Fig 3B). The mixing in these areas is about 10 and 20 times less than the mixing between the surface and sub-surface layers in the Great Bras d'Or Channel. In these deep basins, the currents are generally weak, reducing the potential for vigorous mixing.

In addition to mixing between layers, there can also be a net flow from one to the other. As indicated earlier, if the flow is from the sub-surface layer to the surface layer, it is called upwelling, simply because of the upward transport of water. If the net flow is in the opposite direction, it is called downwelling. Fig 3C shows that in most areas of the Lakes, upwelling prevails and is strongest in North Basin and Bras d'Or Lake. It is somewhat weaker in the other areas. Whycocomagh Bay (east and west) is separated from St. Patrick's Channel by a shallow sill, which effectively isolates the deep areas of the Basin from the rest of the Lakes. This geometry strongly inhibits net flow from one layer to the other. For this reason, Gurbutt and Petrie (1995) assumed that the net flow from the sub-surface to the surface layer in Whycocomagh Bay was zero when they derived their circulation maps. It is evident that downwelling prevails in the Great Bras d'Or Channel (Fig 3C). According to the model, the vertical transport of water is greater in this region than in any other part of the Lakes. 

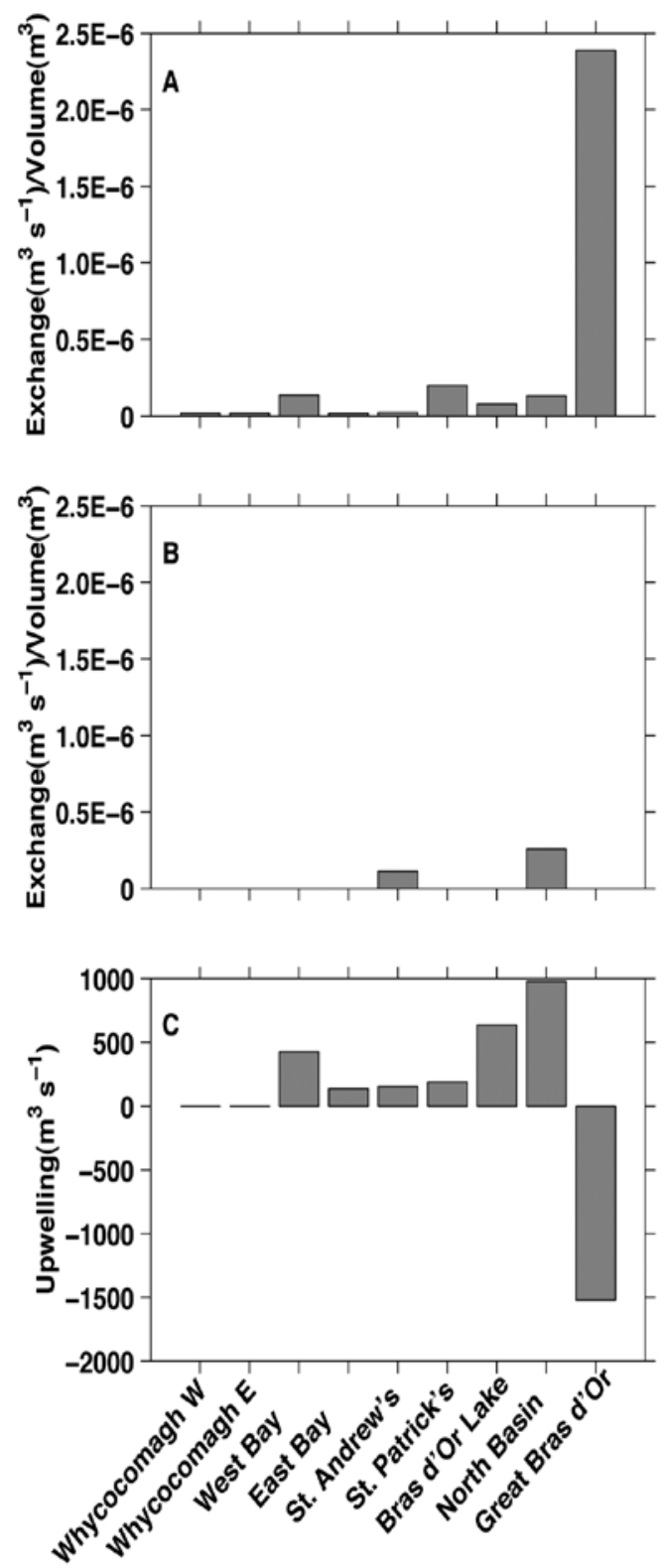

Fig 3 (A) Vertical exchange between the surface and sub-surface layers in the Bras d'Or Lakes. (B) Vertical exchange between the sub-surface and deep layers of the Lakes. (C) Upwelling (positive) or downwelling (negative) from the sub-surface to the surface layers of the Lakes. 


\section{Flushing Times}

One way to establish 'flushing time' is to assume that a dye is put into an area of the Lakes. Allow the circulation and mixing that occur in the Lakes to dilute the dye until its average value reaches a predetermined level. In oceanography, this level is often set at 0.37 of the initial concentration. The time it takes to reach this value is called the flushing time.

Gurbutt et al. (1993) used their model of circulation and mixing to estimate the flushing times for the major regions of the Lakes. The longest flushing times of approximately 2 years were for the sub-surface layers in east and west Whycocomagh Bay, and about 260 days for the deepest basin in St. Andrew's Channel. The shortest flushing times of about 1.5 days were for the surface and sub-surface layers in the Great Bras d'Or Channel. These results are not surprising given the discussion of the mixing and upwelling above.

The decrease in concentration (beginning with a value of 1) over 300 days for the sub-surface layer of Whycocomagh Bay (west), and the deep layers of the North Basin and St. Andrew's Channel is shown in Fig 4. There is a relatively rapid rate of dilution at the start, followed by a more gradual decline. What are the implications of these results? Short flushing times can quickly disperse water-borne pollutants and keep a region of the Lakes well oxygenated. On the other hand, a long flushing time means that dilution of a water-borne contaminant occurs more slowly and that the supply of highly oxygenated waters to a region is reduced.

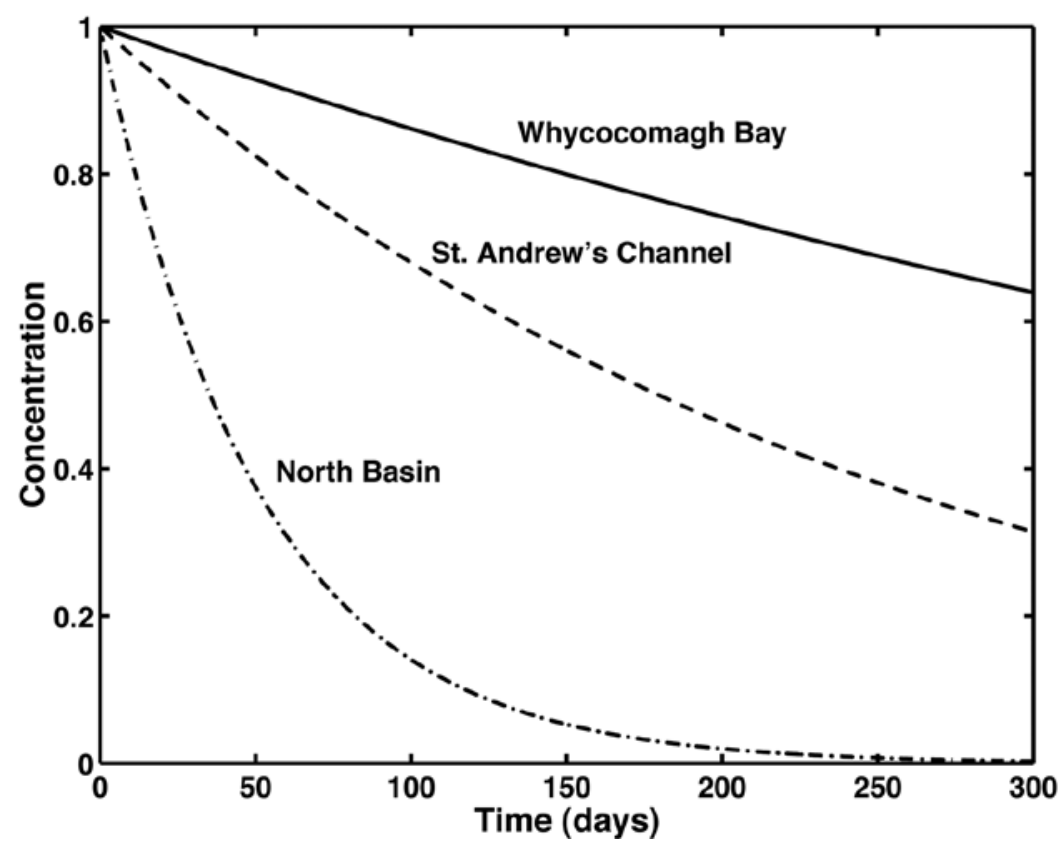

Fig 4 The change of concentration of a dye inserted into the deepest layers of the model of Gurbutt and Petrie (1995). Initial concentration was 1, all areas were run separately. 
Gurbutt and Petrie (1995) considered the effects that flushing times would have on the oxygen concentrations throughout the Lakes. At a given temperature and salinity, there is a limit to the amount of oxygen that ocean water can hold in the dissolved form. At the maximum dissolved oxygen concentration, the water is said to be $100 \%$ saturated. However, at the surface, growing marine plants, wave action and turbulence will often lead to oxygen concentrations that exceed this level; the water is then super-saturated, i.e., exceeding 100\%. Below the oxygen-rich surface layer, oxygen is depleted through fish respiration, benthic uptake (processes related to the bottom sediments), and oxidation of organic material in the water column. This last process is the most significant in the Lakes. On this basis, Gurbutt and Petrie (1995) predicted that the deeper half of both the eastern and western regions of Whycocomagh Bay would be anoxic, i.e, have no dissolved oxygen whatsoever. Oxygen concentrations in the deep areas of St. Andrew's Channel should be reduced by $20-50 \%$ and in the deep part of the North Basin by 5-15\%. In fact, data have indicated that the deep part of the western half of Whycocomagh Bay was anoxic and probably has been in that state for a long time (Fig 5A). The eastern half of the Bay had concentrations reduced by as much as $70 \%$ of their maximum potential value, the deep areas of St. Andrew's Channel (Fig 5B) and North Basin were reduced by $20-45 \%$ and $5-10 \%$ of their maximum potential concentrations. These successful comparisons between model results and observations indicate that the model could be used to examine large scale, long-term pollution issues within the Lakes.
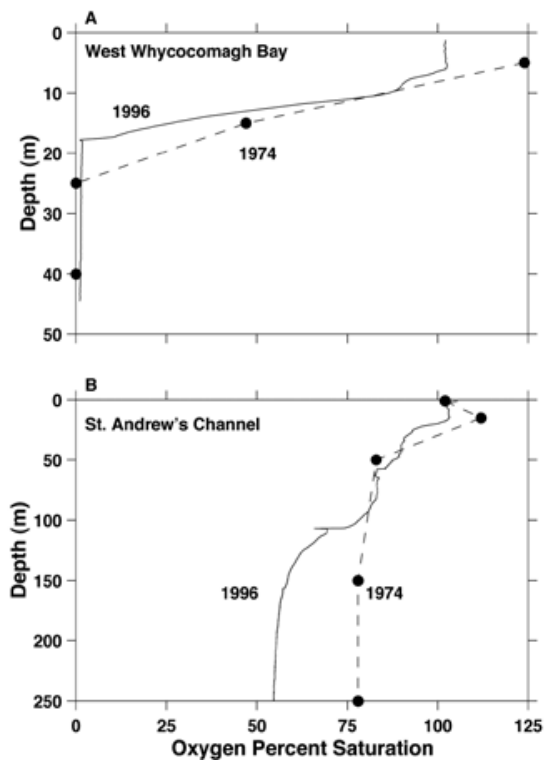

Fig 5 (A) Oxygen percent saturation variation with depth for the western half of Whycocomagh Bay. (B) Oxygen percent saturation for St. Andrew's Channel. Note the oxygen values for the 1974 data are from discrete samples and are determined by Winkler titration. The 1996 observations are from a YSI sensor mounted on the conductivity-temperature-depth (CTD) recording instrument. 


\section{Freshwater Inflow}

One of the major forces that contributes to the circulation in the Lakes is freshwater inflow. The Lakes do not have a single dominant river source. Rather, there are a number of small rivers and brooks that supply the freshwater. In addition, the surface area of the Lakes is a sizable fraction of the land drainage area. Direct rainfall on the Lakes' surface and evaporation from it must be considered when determining the total inflow. Gurbutt et al. (1993) used gauged river inflow measurements, drainage basin areas and the area of the Lakes (for rainfall or evaporation) to determine an annual cycle of freshwater inflow. The annual cycle features a strong pulse of freshwater in the spring associated mainly with snow and ice melt and the tendency for greater rainfall during this season (Fig 6). The monthly average inflow in April and May reaches almost $250 \mathrm{~m}^{3} \mathrm{~s}^{-1}$. There is also a secondary peak in November-December of about $170 \mathrm{~m}^{3} \mathrm{~s}^{-1}$. The weakest inflow occurs during the summer months of July-September at a rate of just above $50 \mathrm{~m}^{3} \mathrm{~s}^{-1}$. This pattern of the annual cycle is typical of the eastern Canadian region.

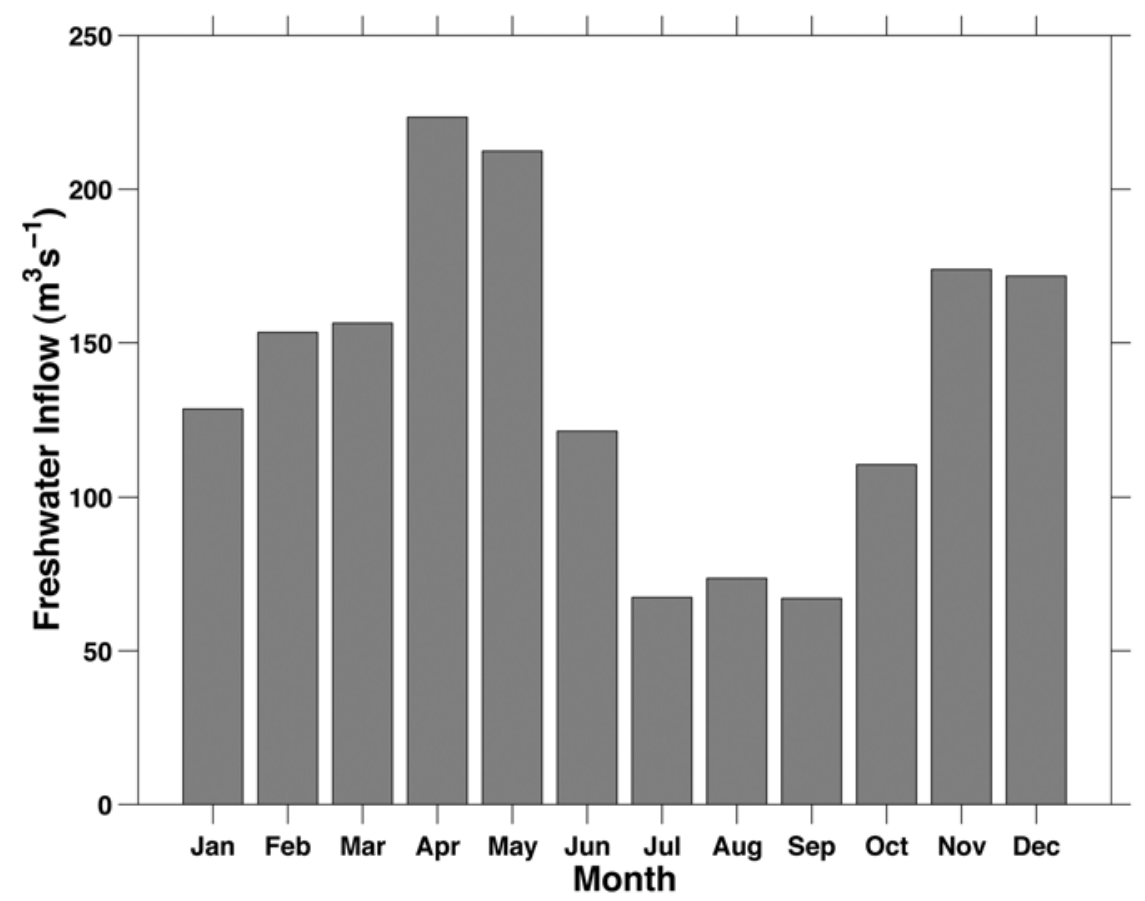

Fig 6 Monthly mean freshwater inflow into the Bras d'Or Lakes.

The overall magnitude of the freshwater inflow is small and would take nearly 7 years to replace the volume of water in the entire Lakes. Despite its relatively weak inflow, the freshwater does have a significant effect on the salinity of the Lakes as we shall see in the next section. This again relates to the restrictive connection between the Lakes and the ocean that controls the amount of saline water that can enter the system. 


\section{Distribution of Temperature and Salinity}

The distributions of temperature and salinity in the Lakes for May and July are shown in Fig 7. The left side of each figure corresponds to Sydney Bight; moving to the right, the data come from the Great Bras d'Or Channel, the North Basin, through Barra Strait into Bras d'Or Lake and finish in East Bay. The locations of the stations are shown in Fig 1.
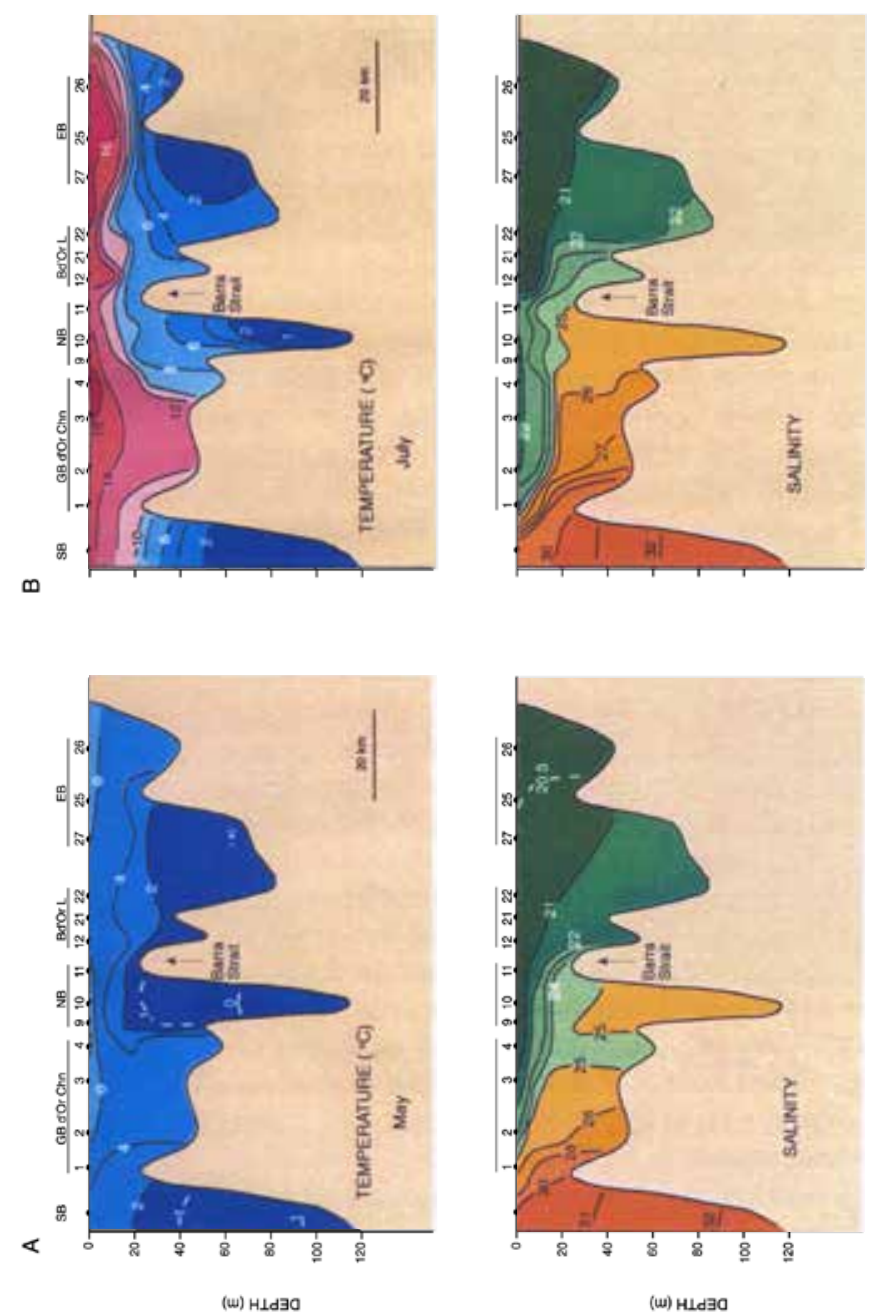

Fig 7 Temperature and salinity sections for the Bras d'Or Lakes (A) May 1974 and (B) July 1974. Sydney Bight (SB) is on the left hand side of each panel, East Bay (EB) on the right, with Great Bras d'Or Channel (GB d'Or Chn), North Basin (NB), Barra Strait, and Bras d'Or Lake (B d'Or L) in between. A line in Fig 1 shows the track of the line of stations. The position of each station where data were collected is shown as a dot and number at the top of each panel. 
During winter, water temperatures fall to roughly $0^{\circ} \mathrm{C}$ in the Lakes. By May, surface temperatures are about $6^{\circ} \mathrm{C}$, but the deeper waters remain close to $0^{\circ} \mathrm{C}$. Temperatures in the Great Bras d'Or Channel show less change with depth than in other parts of the Lakes. This is probably because of the enhanced mixing in this region. Surface salinity in May changes significantly from Sydney Bight where it is about 30 (a salinity of 30 represents $30 \mathrm{gm}$ of salt in $1 \mathrm{~kg}$ of seawater) at the surface, to less than $21 \mathrm{in}$ North Basin, and 20.5 in East Bay. This surface salinity front (large change in a short horizontal distance) reflects the influence of the freshwater inflow into the confined area of the Lakes. Salinity at depth in North Basin is about 25. The average salinity of the Lakes is about 22, substantially less than an equivalent region in Sydney Bight. Given the volume of the Lakes though this adds up to a substantial quantity of salt, $7 \times 10^{11} \mathrm{~kg}$ of salt.

Warming occurs through the spring and summer so that by July, surface temperatures can exceed $16^{\circ} \mathrm{C}$. The change of temperature with depth increases for most of the Lakes but remains smallest in the Great Bras d'Or Channel. Temperature in the deep North Basin is less than $1^{\circ} \mathrm{C}$ and salinity is about 25.5. In East Bay, salinity has increased from its May values, perhaps because the inflow of freshwater has decreased from the spring runoff associated with snow melt and the general increase of rainfall at this time of the year. The influence of the limited exchange with the ocean manifests itself again as a strong change of salinity along the Great Bras d'Or Channel.

Another perspective of the temperature and salinity distributions in the Lakes is gained by examining those properties at a fixed depth (Fig 8). Two surveys, one in May 1974 and the other in September 1996 had sufficient spatial coverage to allow reasonable mapping of the temperature and salinity in approximately the upper $2 \mathrm{~m}$ over most of the surface of the Lakes. Some interesting features and contrasts are evident. Lower temperatures and higher salinities are seen at the mouth of Great Bras d'Or Channel for both surveys. In the September survey, the near-surface temperature was highest in St. Andrew's and St. Patrick's Channels, decreased into Bras d'Or Lake and was lowest in East Bay. It is possible that the low temperatures in East Bay were caused by upwelling driven by local winds when these measurements were taken. Also prominent is the decrease of salinity along St. Patrick's Channel into Whycocomagh Bay. A similar decrease, but not as large, occurs between North Basin and Bras d'Or Lake through Barra Strait. The lowest near-surface salinities were recorded in Denys Basin which is connected to Bras d'Or Lake through a very restricted passage. This restriction limits the influence of ocean waters in the Basin. In May 1974, the highest temperatures and the lowest salinities were found in Whycocomagh Bay at the head of St. Patrick's Channel. The central part of Bras d'Or Lake featured the lowest temperatures. Apart from St. Patrick's and the Great Bras d'Or Channels, the salinity differences were not large throughout the rest of the Lakes. The May 1974 survey did not make measurements in Denys Basin.

Infrared sensors on satellites provide estimates of sea surface temperature for the world's oceans. However the spatial resolution of these sensors is about $1 \mathrm{~km}$, comparable to the widths of the channels in the Lakes. Thus the estimates of sea surface temperature for those areas are contaminated by land effects. We examined a broad range of sea surface temperature products and found that temperatures were only available for the central parts of the North Basin and Bras d'Or Lake.

How deep do the surface features in Fig 8 penetrate below the surface? For temperature and salinity it depends on the time of the year and on the location within the Lakes (e.g., see Fig 7). For the entire area of the Lakes, we calculated the monthly average depth where the temperature differs from the surface value by $1^{\circ} \mathrm{C}$ (Fig 9). We 
Near-surface Temperature, Sept. 1996

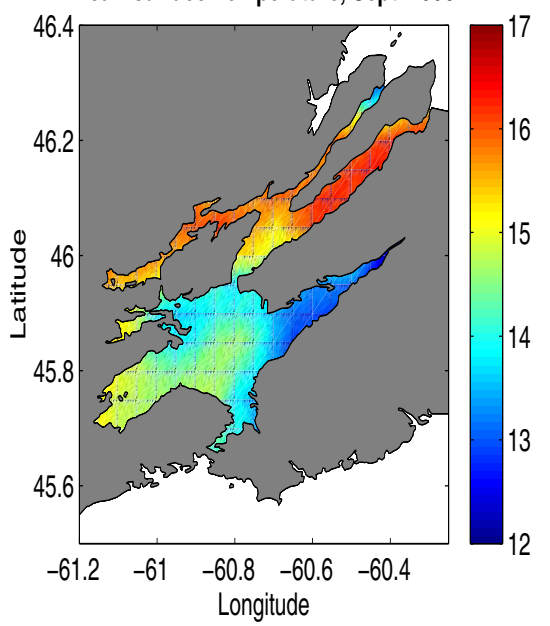

Near-surface Temperature, May 1974

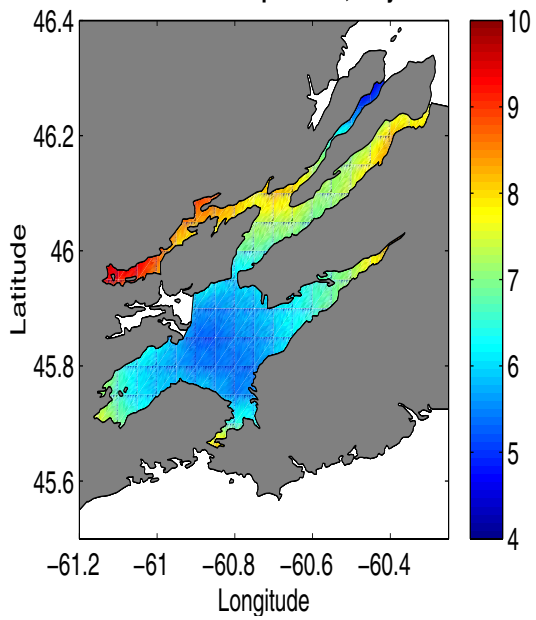

Near-surface Salinity, Sept. 1996
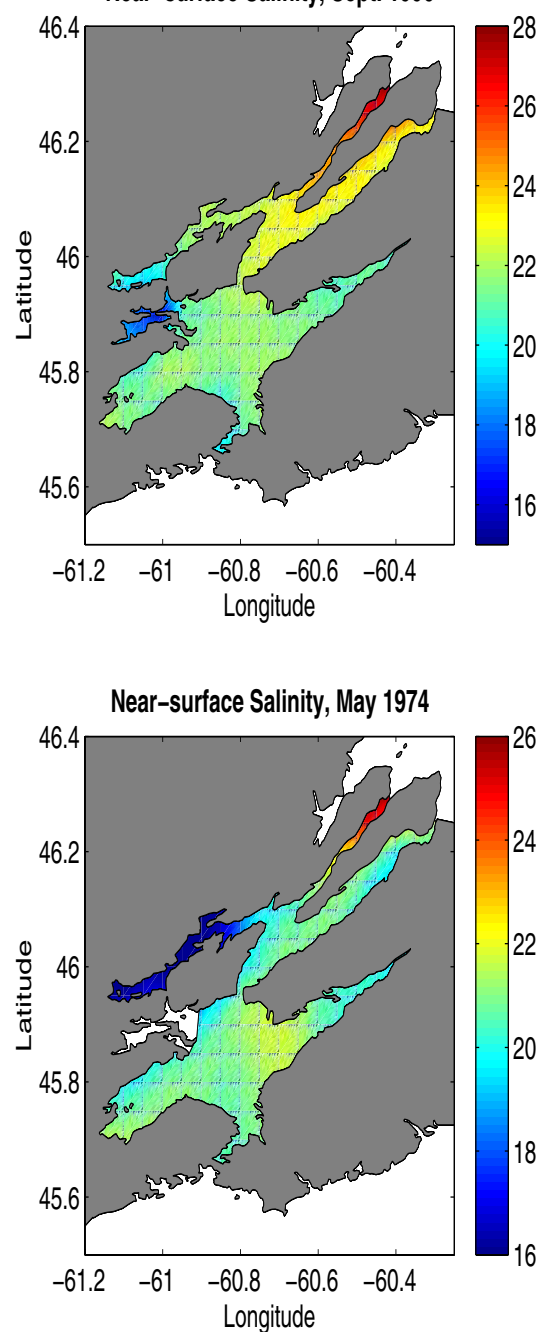

Fig 8 Near-surface (approximately the upper $2 \mathrm{~m}$ ) temperature and salinity from ship surveys in 1996 and 1974. Note that the colour scale changes for each panel and the white areas indicate no data were available to interpolate the temperature and salinity fields.

shall refer to this as the mixed layer depth. Data availability restricted the estimations to the May-November period. The results make sense when compared to other areas. In spring and summer we expect the mixed layer depth to be shallow because the heating from the sun is confined to the near-surface waters and winds are generally weak, thereby reducing the potential for turbulence. The mixed layer depth is about $4 \mathrm{~m}$ for the May to August period with a standard deviation of about $7 \mathrm{~m}$ (Fig 9). The 


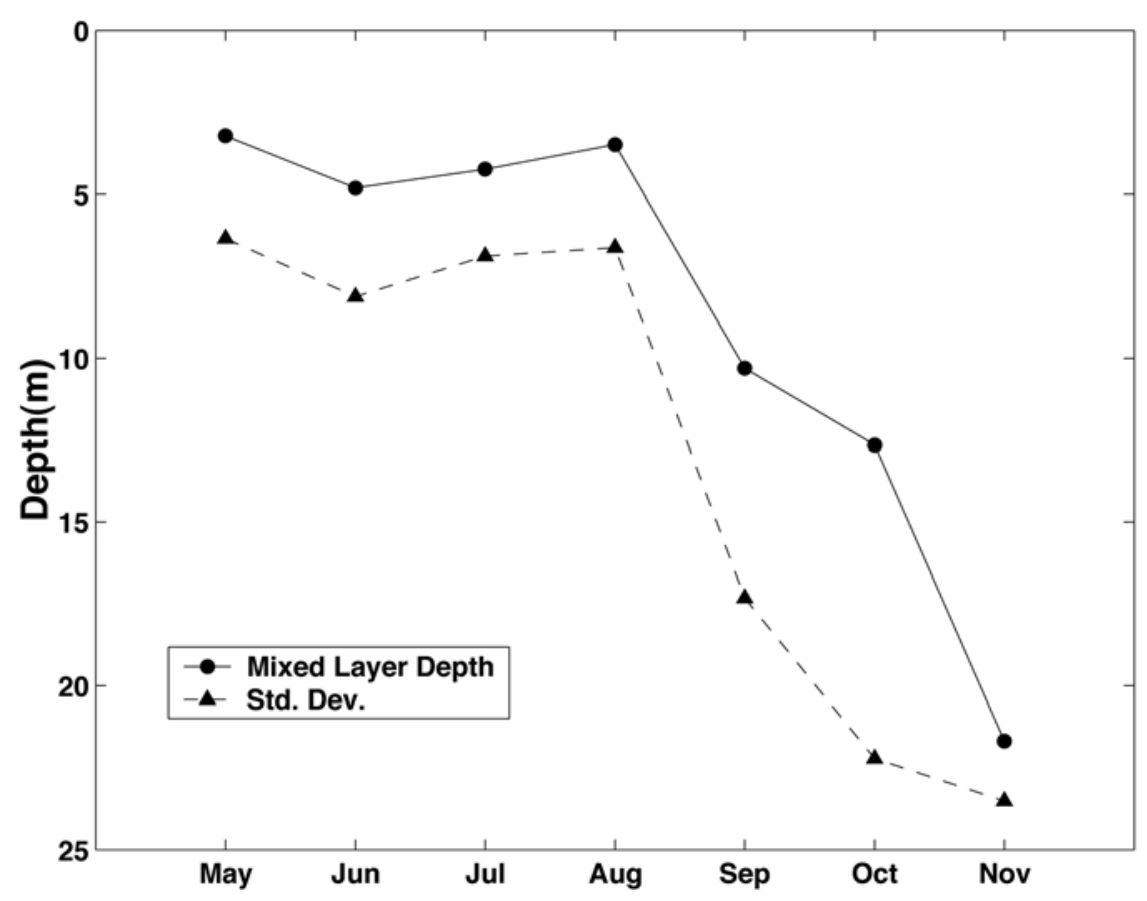

Fig 9 Depth of the mixed layer defined as the mean depth where the temperature changes by $1^{\circ} \mathrm{C}$ from the surface value. The standard deviation is also shown; it provides a measure of the scatter of the individual layer depths about the mean.

standard deviation indicates that there is significant variability of this depth throughout the Lakes, reflecting in part the tidal mixing, and consequently deeper mixed layers, that occurs in areas such as the Great Bras d'Or Channel and Barra Strait. Towards the end of the summer and in the early fall, solar heating decreases, and winds and the frequency of storms generally increase. Thus there is the potential to deepen the mixed layer. That is indeed what is observed (Fig 9). By November, the layer is on average about $22 \mathrm{~m}$ deep and still exhibits considerable variability, reflected in the standard deviation of about $24 \mathrm{~m}$.

It is evident from Fig 7 that the temperature and salinity properties throughout the Lakes change markedly during the summer period. Continuous records from the Great Bras d'Or Channel and Barra Strait for 1998-99 (Fig 10), indicate that substantial changes occur during the year (see Fig 1 for locations). The salinity in the year-long record from Great Bras d'Or Channel ranges from about 22 to 29 (Fig 10A). With a maximum near-surface salinity daily change of 5 ; this gives a spiky appearance to the record. There are also longer term changes evident such as the overall decrease of salinity from winter to spring. This is related to the increased freshwater inflow in the latter period (Fig 6).

The cause of the rapid variations becomes evident when a shorter portion of the same record is examined (Fig 10B). The plot shows that there are approximately two large changes of salinity during a day. This variation is caused by the strong tidal currents 

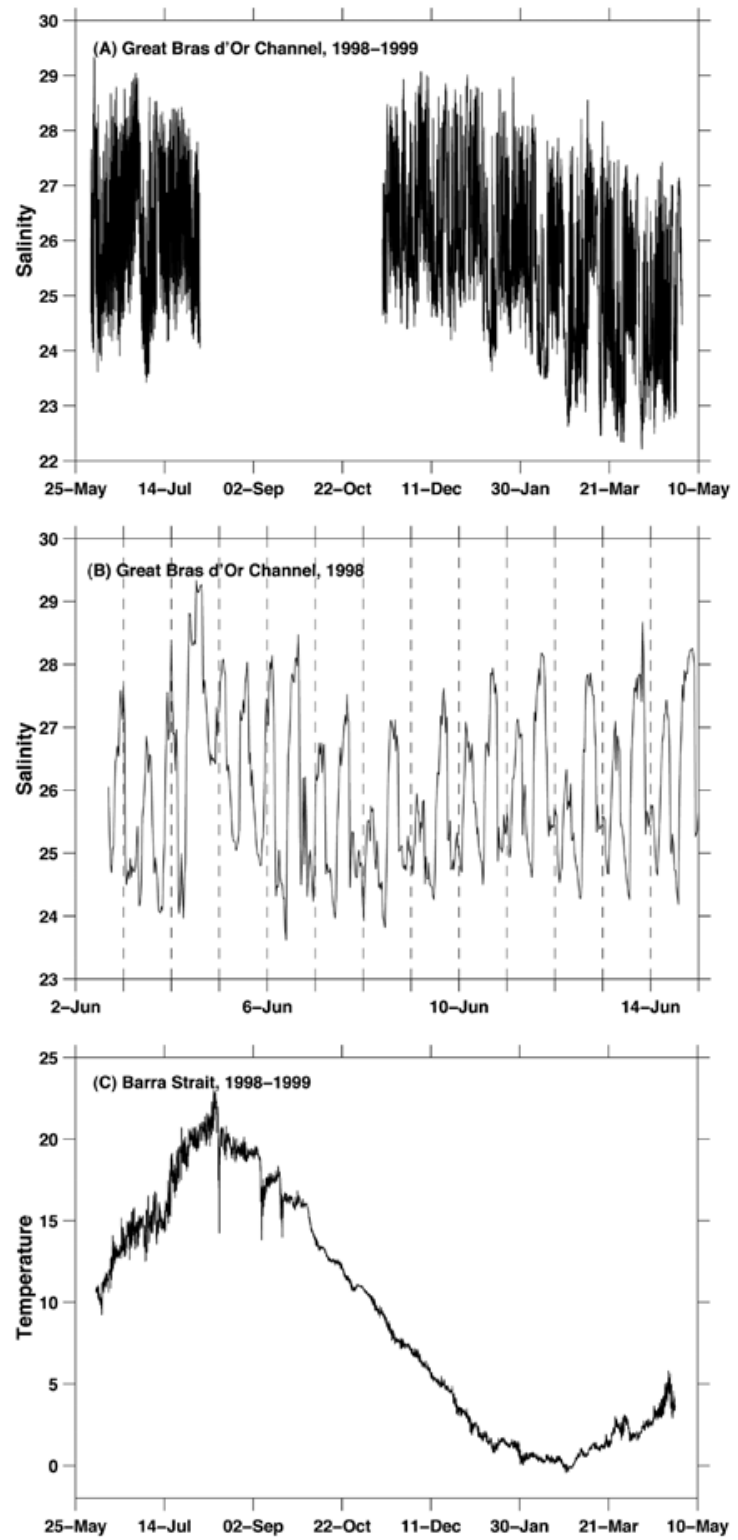

Fig 10 (A) Salinity time series from the Great Bras d'Or Channel. There are two records separated by a gap. The first record is from a depth of $4 \mathrm{~m}$, the second from $3 \mathrm{~m}$. (B) Start of the salinity time series shown in (A). (C) Temperature time series from Barra Strait. The first record, from $4 \mathrm{~m}$, runs from June to early October,1998; the second, from 10 m, runs from October 1998 until April 1999. 
moving the salinity front at the mouth of Great Bras d'Or Channel (Fig 7) back and forth past the sensor. On one part of the cycle, the sensor measures water whose properties are more characteristic of Sydney Bight; the flow then reverses and $6 \mathrm{~h}$ later the sensor measures water with properties shifted towards those of the Bras d'Or Lakes.

The annual cycle of temperature at Barra Strait for 1998-1999 is shown in Fig 10C. Peak temperatures of about $23^{\circ} \mathrm{C}$ were reached in mid-August and decreased to a minimum of about $-0.25^{\circ} \mathrm{C}$ in late February.

Observations suggest that the changes in the deep basins are very small, even over periods as long as $75 \mathrm{y}$. In Fig 11 we show data from St. Andrew's Channel for depths equal to or greater than $100 \mathrm{~m}$. The earliest observations are from 1924, the latest from 2000 with large gaps between years until the late 1990s. The data indicate that the temperatures range from -1 to $1^{\circ} \mathrm{C}$ with a median value of about $0.33^{\circ} \mathrm{C}$; salinity has a range of about 24.8 to 26.5 with a median value of 25.43 . The coolest temperatures and highest salinities are generally for the years 1924 and 1935. The warmest temperatures and the lowest salinities were for the years 1998-2000. These observations were compared to the variations of Sydney air temperatures and freshwater runoff from the nearby gauged Northeast Margaree River. The variations generally fit, high air temperatures led to high deep water temperatures, and low freshwater input led to high deep salinities and vice versa. These results indicate the importance of local processes, as well as inflow from Sydney Bight, in determining the properties of the deep waters of the Lakes.

There is a striking contrast between deep waters in the Lakes and the adjacent ocean. The temperature and salinity of waters at the same depth from the Laurentian Channel east of Sydney Bight, the nearest area with water depths comparable to St. Andrew's Channel, are about $5.8^{\circ} \mathrm{C}$ and 34.5 . These values are substantially higher than the $0.33^{\circ} \mathrm{C}$ and 25.43 for temperature and salinity observed in St. Andrew's Channel. Two processes probably are most prominent in setting the deep water properties in the Lakes: local winter convection and advection, i.e. flow, from Sydney Bight with strong mixing occurring in the Great Bras d'Or Channel. During winter convection, cooling causes the near surface waters to become more dense than the waters below them. The denser waters sink and fill up the deep areas of the Lakes. Water from Sydney Bight is modified as it enters the Lakes through the Great Bras d'Or Channel and, if sufficiently dense, flushes the deeper areas of the Lakes, replacing the water that was present there. Currently a program is underway to determine the relative strengths of these two processes.

\section{Currents in the Bras d'Or Lakes}

Current observations were made by Krauel (1975a) during the Bras d'Or Lakes surveys in 1973 and 1974. Recording current meters were mounted on a mooring cable and suspended above an anchor by a sub-surface float. In the open areas of the Lakes, the currents were generally so weak that for a large percentage of the time no flow was registered. In the Great Bras d'Or Channel and Barra Strait, the currents were so strong that the moorings were tilted, a process that can lead to poor instrument performance and degraded data quality. In addition, depending on the strength of the current, the instruments would record at different depths: strong flows cause large mooring tilts, pushing the instrument deeper. This can make the data difficult to interpret.

In 1998-1999, bottom-sited acoustic Doppler current meters were moored in Barra Strait and just inside the mouth of the Great Bras d'Or Channel (Fig 1) These 


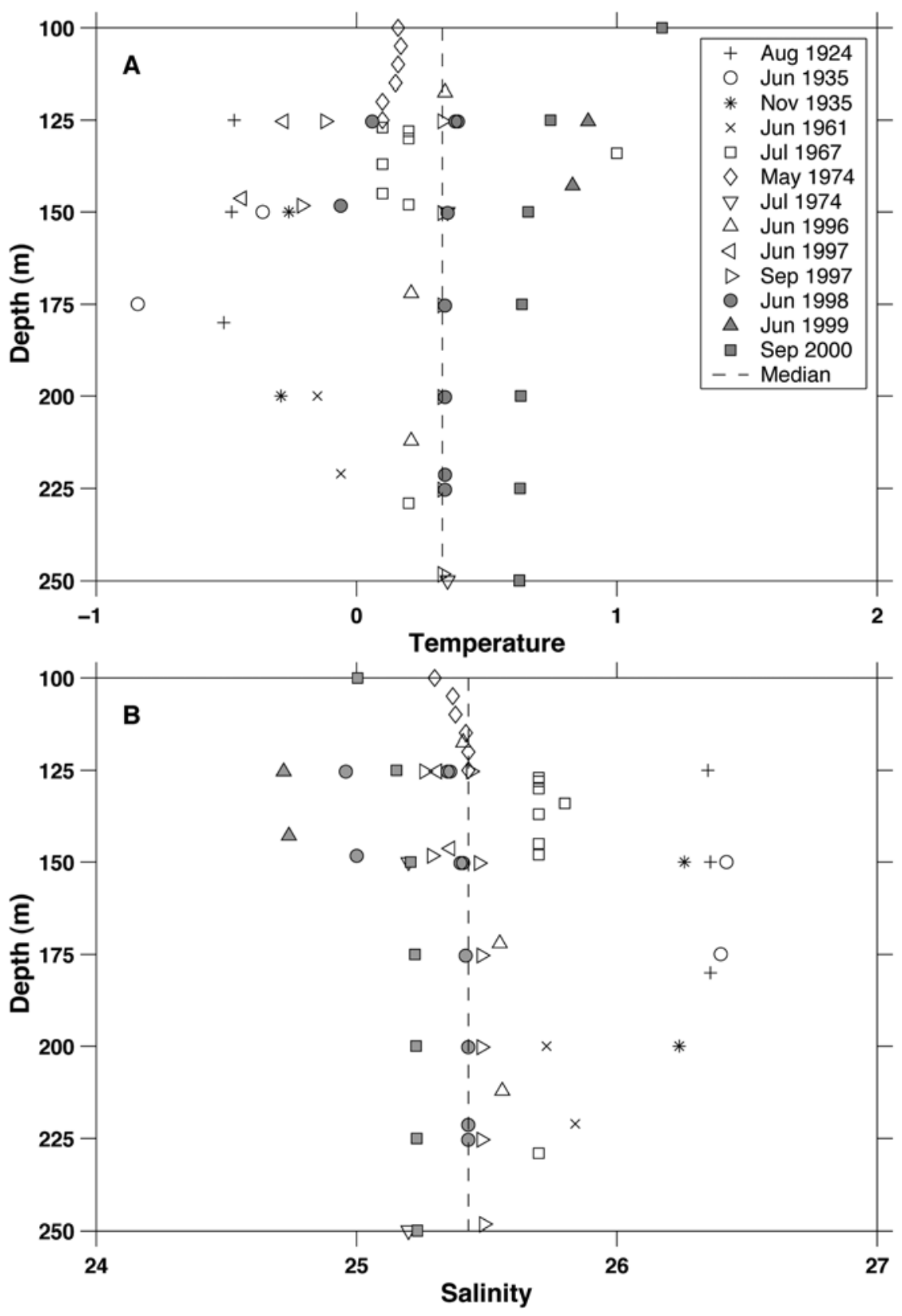

Fig 11 (A) Temperature and (B) salinity data from St. Andrew's Channel for depths equal to or greater than $100 \mathrm{~m}$, spanning the years 1924-2000. 
instruments sit on the bottom and measure the current by transmitting an upward pulse of sound and recording its echo reflected by small organisms and particles in the overlying water. If the echo has a higher (lower) frequency than the original sound, the reflecting particle is moving with the current towards (away from) the instrument. This change in sound frequency is known as the Doppler Shift. Four separate beams of sound are used so that the current speed and direction can be resolved. The return signals are processed in the instrument and estimates of the currents for each $1 \mathrm{~m}$ vertical interval are recorded. This instrument provides estimates of the current over most of the water depth without the problems that arise from tilting of ordinary meters.

A sample of the current records from the Great Bras d'Or Channel and Barra Strait illustrate the characteristics of the flow (Fig 12A, B; a negative sign means the water is flowing into the Lakes). At both locations a strong tidal component is evident as the rapid change of the along channel current approximately every $12 \mathrm{~h}$ (semi-diurnal) over the length of the record. The tidal component is considerably stronger in the Great Bras d'Or Channel with currents ranging from about $-250 \mathrm{~cm} \mathrm{~s}^{-1}$ to about 150 $\mathrm{cm} \mathrm{s}^{-1}$ (Fig 12A). The time series of current is biased towards the inflow side of the figure, i.e., most of the negative values are larger than the positive ones. This indicates that the average flow at this depth, $18.5 \mathrm{~m}$, is into the Lakes. At Barra Strait the flows range from about -40 to $40 \mathrm{~cm} \mathrm{~s}^{-1}$; however, at the depth $(3.9 \mathrm{~m})$ of this series, the bias is generally positive (Fig 12B), i.e. the $3.9 \mathrm{~m}$ flow is out of the Lakes.

These records run from the fall of 1998 to the spring of 1999. Fig 13 shows the mean, along channel currents and the amplitude associated with the tidal currents at both locations. In the Great Bras d'Or Channel, the mean flow is out of the Lakes at $4.5 \mathrm{~m}$ (Fig 13A). Below $4.5 \mathrm{~m}$, the current is into the Lakes. The current meter is unable to estimate the flow in the upper $4 \mathrm{~m}$ because of inherent technical limitations. However,

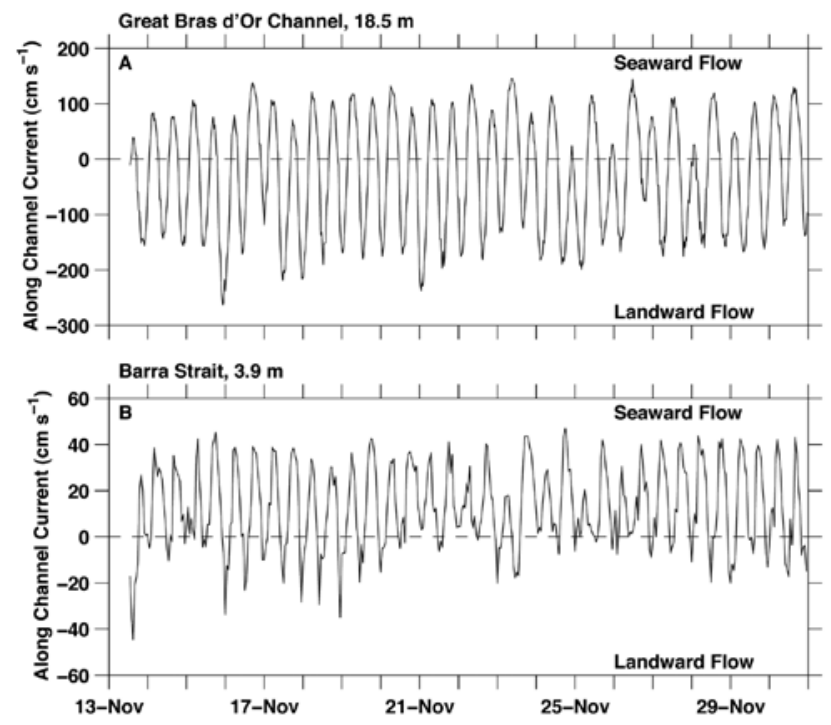

Fig 12 Current meter records from (A) $18.5 \mathrm{~m}$ depth inside the mouth of the Great Bras d'Or Channel and (B) from 3.9 m depth in Barra Strait in November, 1998. Note that a positive value indicates flow from the Lakes to the ocean and vice versa. 
the flow in the 0-4 m range must be strongly out of the Lakes, otherwise they would fill with water and overflow the shore. As noted earlier, there must be a balance between inflow and outflow, in fact the outflow should exceed the inflow on average by the amount of freshwater that runs into the Lakes. On the other hand, at Barra Strait the mean flow is strongly out of the Lakes in the upper $14 \mathrm{~m}, 11 \mathrm{~cm} \mathrm{~s}^{-1}$ at $4 \mathrm{~m}$ depth. The flow then oscillates between positive and negative values from 15 to $44 \mathrm{~m}$ (Fig 13C). We think that the mean flow from 0 to $4 \mathrm{~m}$ is still out of the Lakes. The imbalance seen here indicates that we have not sampled the Strait adequately. It probably means that we should have had current meters at more locations across the Strait.

The semi-diurnal tidal amplitudes in the Great Bras d'Or Channel are about $90 \mathrm{~cm}$ $\mathrm{s}^{-1}$ at all depths (Fig 13B). There are a number of different tidal components that have periods of about 12 hours. The amplitude shown in the figure is the combined flow caused by all of the semi-diurnal components (discussed in more detail in the next section). The amplitudes are considerably smaller in Barra Strait, varying from about 5 to $20 \mathrm{~cm} \mathrm{~s}^{-1}$ (Fig 13D). The strong variation with depth is caused in part because the
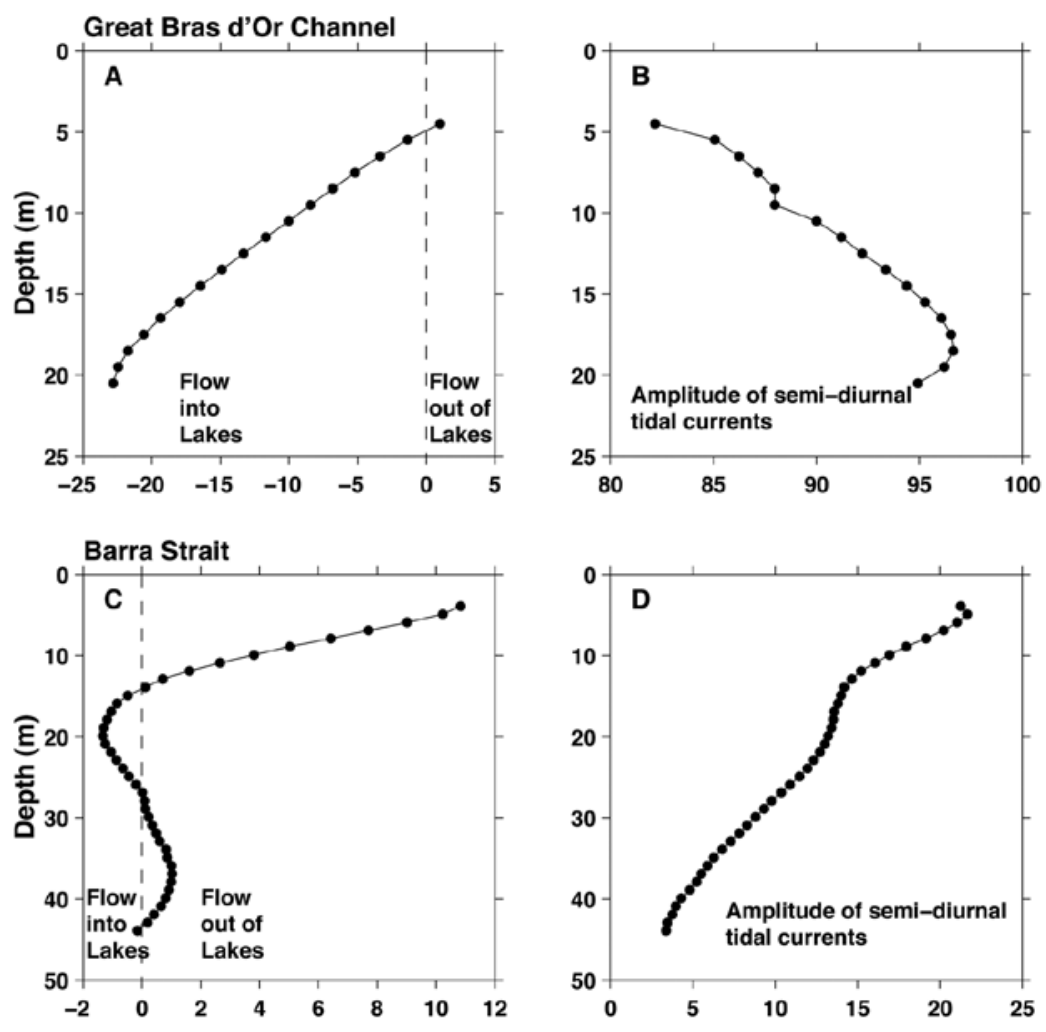

Fig 13 (A) Mean current along the channel axis for the period November 1998 -April 1999 for the Great Bras d'Or Channel. (B) Amplitude of the semi-diurnal tidal currents for the Great Bras d'Or Channel. (C) Same as (A) except for Barra Strait, October 1998 - April 1999. (D) Same as (B) except for Barra Strait, October 1998 - April 1999. 
instrument was placed in a relatively deep hole in the middle of the Strait.

The currents in the Great Bras d'Or Channel are notable by any standard. The flows on occasion approach $3 \mathrm{~m} \mathrm{~s}^{-1}$. In the Canadian east coast region, similar currents are generally only seen in the Bay of Fundy. These strong currents cause considerable mixing in the Great Bras d'Or Channel; the currents in Barra Strait, though weaker, still have the potential to generate significant mixing. Associated with the strong tidal currents are changes in sea level that have a distinct character in the Lakes.

\section{Sea Level in the Bras d'Or Lakes}

Tidal Elevations The effect of tides and the problem of sea level prediction in the Bras d'Or Lakes has intrigued the public for a long time. The Yachtsman's Guide to the Bras d'Or Lakes (1987) contains the interesting and puzzling statement: "tidal predictions ... are a matter of consternation. In a number of instances the lunar component of our semi-diurnal tidal area defies the 12-hour period by as much as 5 days at Barra Strait". Before dealing with this statement, we shall first indicate the dominant tidal component in the Lakes and also examine non-tidal influences affecting sea level.

The tides in the oceans are caused by the gravitational attraction of the sun and the moon. The orbits of the sun-moon-earth system follow complicated but predictable patterns that give rise to a number of tidal components with different periods of variability. The tides in the Bras d'Or Lakes are not the result of direct sun-moon gravitational forcing on the lake waters but rather are a response to the tides in Sydney Bight.

The tides in Sydney Bight have 5 major components (or constituents) that are called $\mathrm{M}_{2}, \mathrm{~N}_{2}, \mathrm{~S}_{2}, \mathrm{~K}_{1}$, and $\mathrm{O}_{1}$ with amplitudes of $36.8,7.6,10.9,7.7$, and $8.2 \mathrm{~cm}$ respectively. The first 3, known as semi-diurnal tides, have periods of roughly one half a day (i.e., they have 2 high and 2 low values each day), the last 2, called diurnal tides, have periods of approximately one day. The largest one by far is the $M_{2}$ tide (period 12.42 hours) which is the principal lunar constituent (the one mentioned by The Yachtsman's Guide to the Bras d'Or Lakes) and is caused by the moon's gravitational attraction on the world's oceans. We consider only this major component in the following discussion.

The amplitude of the $M_{2}$ tide decreases rapidly as it enters the Great Bras d'Or Channel (Fig 14A). The tide at Big Bras d'Or is reduced by more than one half (to 16 $\mathrm{cm})$, compared to its amplitude at North Sydney of $36.8 \mathrm{~cm}$. By Seal Island Bridge it has decreased again to $7.3 \mathrm{~cm}$. The $M_{2}$ tide continues to decrease as it moves farther into the Lakes having amplitudes of $4 \mathrm{~cm}$ at lona and $3 \mathrm{~cm}$ at Baddeck. There is no appreciable tide at Whycocomagh. In the Bras d'Or Lake, at Marble Mountain, Johnstown Harbour and Eskasoni, this component is remarkably constant at about $4.5 \mathrm{~cm}$, slightly larger than in the North Basin. Not only does the amplitude of the principal component of the tides decrease as it enters the Lakes but the time of high water associated with it varies markedly relative to the tide at North Sydney (Fig 14B). In the Great Bras d'Or Channel, high water occurs earlier than it does at North Sydney by as much as $30 \mathrm{~min}$. This lead is caused primarily by the strong frictional effects in the Channel (see Petrie 1999; Proudman 1953). At Baddeck and Iona the tide is approximately $3 \mathrm{~h}$ later than at North Sydney, and finally in the Bras d'Or Lake it is about $4 \mathrm{~h}$ later. Over most of the Lakes, the time of high water is considerably later than it is in North Sydney. Petrie (1999) modelled the $M_{2}$ tidal component and showed that friction and the geometry of the Lakes were the major contributors to the variations of tidal amplitude and timing. 
Conceptually the response of the tides in the Lakes inside of Great Bras d'Or Channel can be thought of in the following way. In Sydney Bight, sea level associated with the $\mathrm{M}_{2}$ tide is changing from high to low then back to high every 12.42 hours. Consider the case when the tide in the Bight is rising. This change enters the Lakes primarily through the Great Bras d'Or Channel. However, the Channel is narrow and generally shallow; in order to change the water level in the Lakes by the same amount as in Sydney Bight, the currents must be strong. As we saw in the last section, the currents are very strong in some places. But strong currents generate a lot of turbulence or friction as they flow over the rough ocean bottom. This friction opposes the flow of
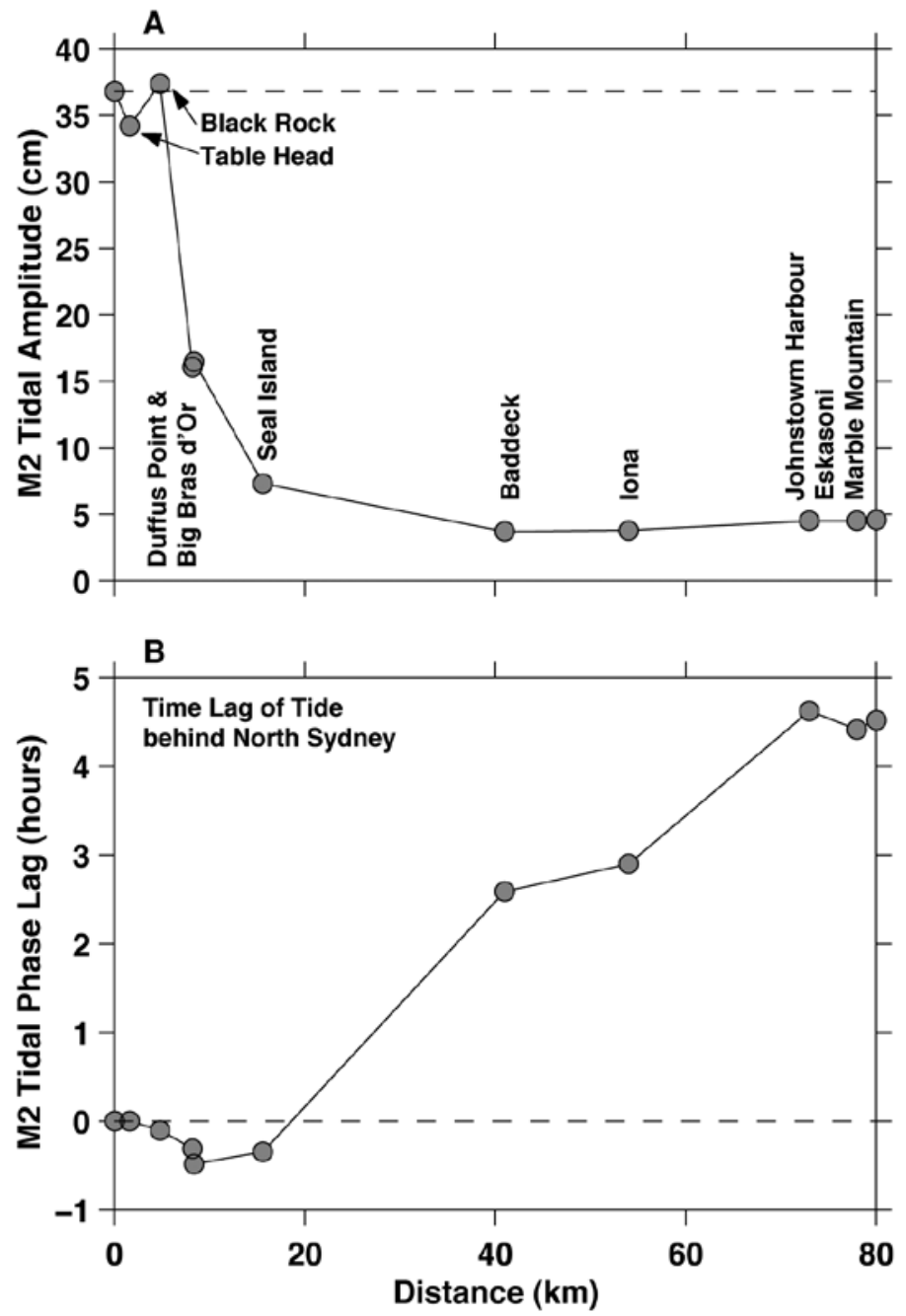

Fig 14 (A) Amplitude $(\mathrm{cm})$ of the $\mathrm{M}_{2}$ tide in Sydney Bight and progressively farther into the Lakes. (B) Delay (hours) of the tide behind high tide at North Sydney. 
water into the Lakes causing a loss of energy; consequently, the tidal amplitude in the Lakes is not as large as it is in Sydney Bight. Even when sea level is starting to fall in Sydney Bight, it still can be higher than it is in the Lakes because the tidal amplitude there is not as large. Water will continue to flow into the Lakes, raising the sea level more. Therefore, high water in the Lakes will occur later than high water in Sydney Bight. When sea level in Sydney Bight falls below the level in the Lakes, the tidal currents will reverse and flow out of the Lakes.

Non-tidal Variations of Sea Level The tides are not the only cause of sea level variations in the Bras d'Or Lakes. Changes in atmospheric pressure, winds and sea level variations in the Gulf of St. Lawrence that move into Sydney Bight are also major factors. Atmospheric pressure changes over Sydney Bight were responsible for large fluctuations in sea level detected by the gauges that were moored in the Lakes in 1973 and 1974 (Petrie, 1999). The response of the ocean to atmospheric pressure changes is known as the inverted barometer effect because higher (lower) pressure leads to lower (higher) sea level. The time scales for these changes to occur are generally from several days to weeks. For the Bras d'Or Lakes, this mechanism works as follows.

High atmospheric pressure over Sydney Bight and the Bras d'Or Lakes region tends to push the water towards areas of the ocean where the atmospheric pressure is lower. Weather systems are generally large, so the low pressure region could be thousands of kilometers distant. It is however, easier to move water away from the Bight than from the Lakes because the Great Bras d'Or Channel restricts the movement of water out of the latter. Sea level thus falls first in Sydney Bight, leaving sea level in the Lakes higher. The difference in sea level causes water to flow from the Lakes into the Bight until a balance is reached. If, over the next few days, the atmospheric pressure in the region decreases, the process will reverse. Sea level will rise in Sydney Bight faster than in the Lakes, a sea level difference will be generated and water will flow into the Lakes through Great Bras d'Or Channel. Thus, sea level in the Lakes responds to sea level variations in Sydney Bight.

Fig 15A, B show sea level records from North Sydney and Seal Island. The tidal and non-tidal variations (Fig 15A) behave quite differently; the former, primarily made up of the $\mathrm{M}_{2}$ tide and seen as the rapid, spike-like changes in the diagram, decreases markedly between Sydney Bight and Seal Island. As discussed above, they continue to decrease with distance into the Lakes. However, it is apparent that the non-tidal variations do not decrease much between North Sydney and Seal Island. This is more clearly illustrated in Fig 15B where the tides have been removed from the record. The more gradual changes seen in the North Sydney record decrease by a very small amount in the Great Bras d'Or Channel. In examining all of the records from the interior of the Lakes, Petrie (1999) found that the maximum reduction of the non-tidal variations (to be more precise, variations that have periods longer than 1 day) was about $15 \%$. Therefore, the non-tidal sea level variations retain at least $85 \%$ of their magnitude as they move into the Lakes. Moreover, within the Lakes, these variations have been observed to be up to $50 \mathrm{~cm}$, about 10 times larger than the tides.

The cause of much of the slowly-varying sea level changes seen in Fig 15B is apparent when the atmospheric pressure is compared to the sea level records. In Fig 15, the atmospheric pressure variations have been inverted; i.e. high values are plotted downward, low values are plotted upward. Most of the fluctuations seen in the inverted atmospheric pressure corresponds to the sea level data from North Sydney and the Lakes.

Why are the tides reduced so drastically yet the non-tidal variations pass into the Lakes largely unaffected? The key to understanding this is to recall how rapidly the 
variations occur. The tides change over a day (diurnal) or half day (semi-diurnal). For $\mathrm{M}_{2}$, this means that sea level goes from its lowest to highest point in $6.21 \mathrm{~h}$. In order for sea level in the Lakes to respond to these changes, water must flow very rapidly through the Great Bras d'Or Channel, first into the Lakes as sea level in Sydney Bight increases, then out as sea level falls. The friction that takes energy out of the tides is considerably more for currents with a high velocity than for those with a low velocity. (Technically if a current doubles, its frictional effect increases by four times.) Thus, friction becomes very important in decreasing the flow and the vertical movement of the sea surface. Consequently, there is a strong reduction of the elevation changes
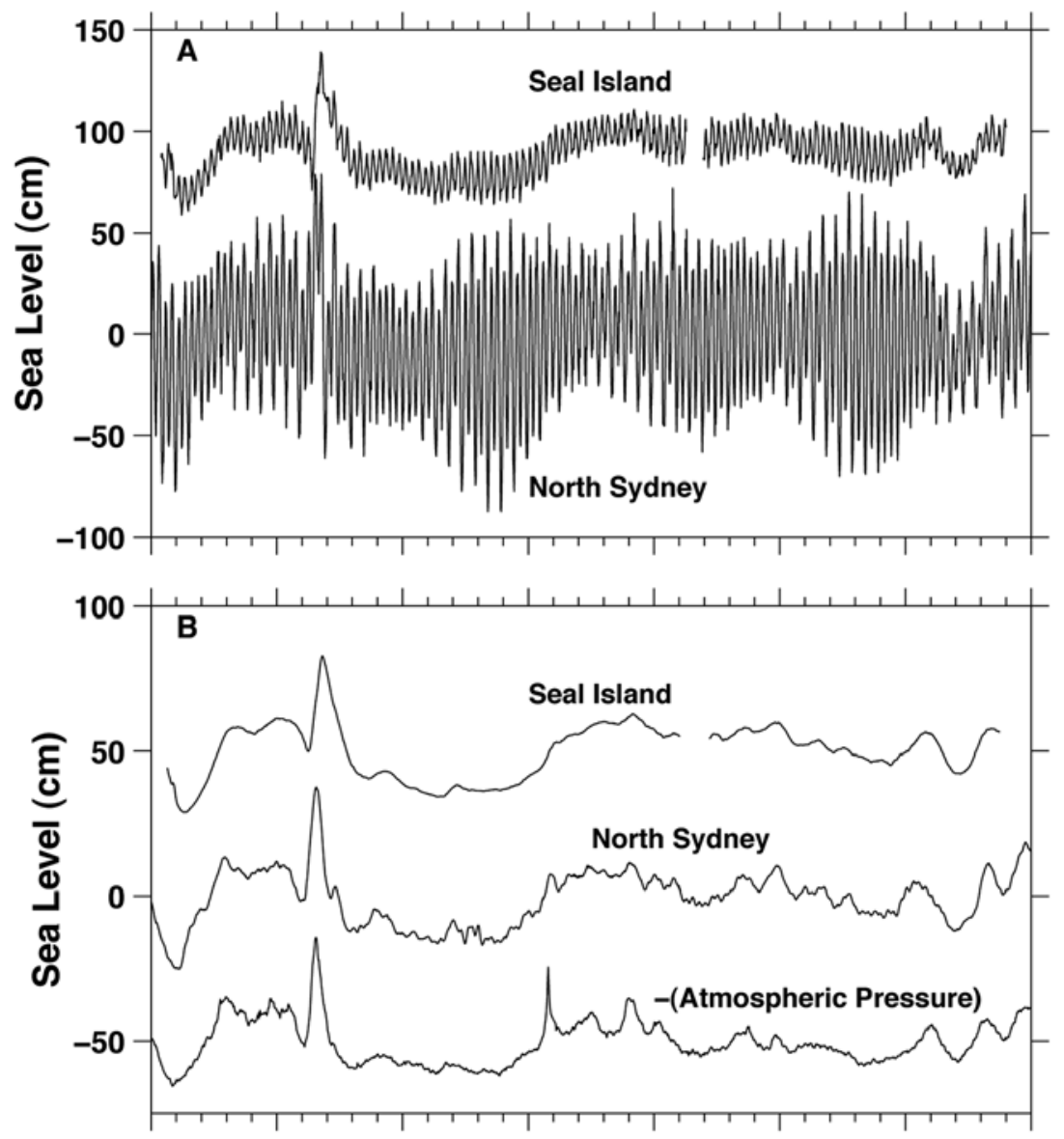

5-Jun 15-Jun 25-Jun 5-Jul 15-Jul 25-Jul 4-Aug 14-Aug

Fig 15 (A) Sea level records from North Sydney and Seal Island in 1973. (B) The same records after the tides have been removed. Also shown is the negative of the atmospheric pressure variation after the mean value has been subtracted, i.e. it is the inverted atmospheric pressure. Note in both figures the Seal Island record has been offset for clarity as has the atmospheric pressure in (B). 
associated with the tides. On the other hand, sea level variations associated with non-tidal changes, such as from the inverted barometer effect, occur more gradually, over many days or even weeks (Fig 15B). The currents associated with these changes are much smaller than those associated with the tides since there is more time to move the water into and out of the Lakes. As a result, the frictional losses are not large and the sea level changes are only slightly smaller in the Lakes than they are in Sydney Bight. Petrie (1999) gives a more rigorous, mathematical explanation of this phenomenon.

Returning to the statement from "The Yachtsman's Guide to the Bras d'Or Lakes" we can speculate that the authors thought that only tides caused water level variations in the Lakes. They did not realize that non-tidal changes can be larger and vary more slowly. Perhaps they matched the highest predicted tide at North Sydney with the highest observed water level in the Lakes.

Surface waves Surface waves, the rapid vertical movement of the water's surface caused by wind, are another form of sea level variation. On the Lakes, their periods (the time between successive peaks or troughs at a fixed point) are primarily in the 2-4 second range. Environment Canada placed a wave rider buoy in the North Basin in 1992 and in the Bras d'Or Lake in 1993 (Fig 1). Both moorings recorded for about 6 months from the spring to the fall. Wave heights (the distance from the wave trough to its crest) were measured and their characteristics summarized every hour.

One of the parameters recorded by the buoys was the significant wave height (SWH). The SWH is determined by averaging the highest one-third of all the waves recorded in a specified time interval. Wave height generally increases with the strength of the wind, its duration, and with the distance that it blows over the water from land to the buoy site. This distance is called the fetch.

In the North Basin, the fetch for the dominant wind direction in the records was $11 \mathrm{~km}$; in the Bras d'Or Lake, the fetch was $28 \mathrm{~km}$. For the same wind strength and duration, we expect larger waves in Bras d'Or Lake than in the North Basin because of the former's longer fetch.

The results from the observation program are shown in Fig 16A, B. Note that the resolution of the $\mathrm{SWH}$ is $0.1 \mathrm{~m}$, i.e., there are only values at $0,0.1,0.2 \mathrm{~m}$ etc. It is also traditional to use the wind speed in knots rather than metric units. The solid dots are the individual estimates of SWH, 3951 points in 1992 and 3891 points in 1993. The open circles connected by a line are the median values of wind speed plotted at every interval of 0.1 meters of SWH. The median is the value, such that half the values are greater, half are less. The broken line is the predicted relationship from a formulation of Bretschneider (e.g., Khandekar (1989)).

The waves in the North Basin are smaller than those in the Bras d'Or Lake for the same wind speed (Fig 16A, B). This is expected given that the fetch in the latter is greater. The idealized model gives qualitatively reasonable results but it generally overestimates the SWH in North Basin compared to the observations. In the Lake, the model agrees well with the observed median wave height. A more complete comparison would involve separating the wave parameters according to the wind direction. For each wind direction a separate model result would be calculated since the fetch changes and would be compared with the observed SWH. However, the relationships in Fig 16 can serve as a good guide for predicting the SWH in the Bras d'Or Lakes.

\section{Ice Cover in the Bras d'Or Lakes}

Over the past 3 years (1998-2000), the winters have been relatively mild and consequently ice cover over the Lakes has been below normal. On the other hand, 
we know that the flights of the Silver Dart relied on the ice of Baddeck Bay to serve as a runway for the first powered flights in the British Empire. It is apparent that ice cover varies substantially from year to year. Clearly a long time is required to collect enough observations to establish the average winter ice cover.

Environment Canada has been compiling ice statistics for the east coast since the early 1960s. We have used their maps of ice cover collected over 30 years to calculate the mean conditions for different areas of the Lakes. These have been combined to give
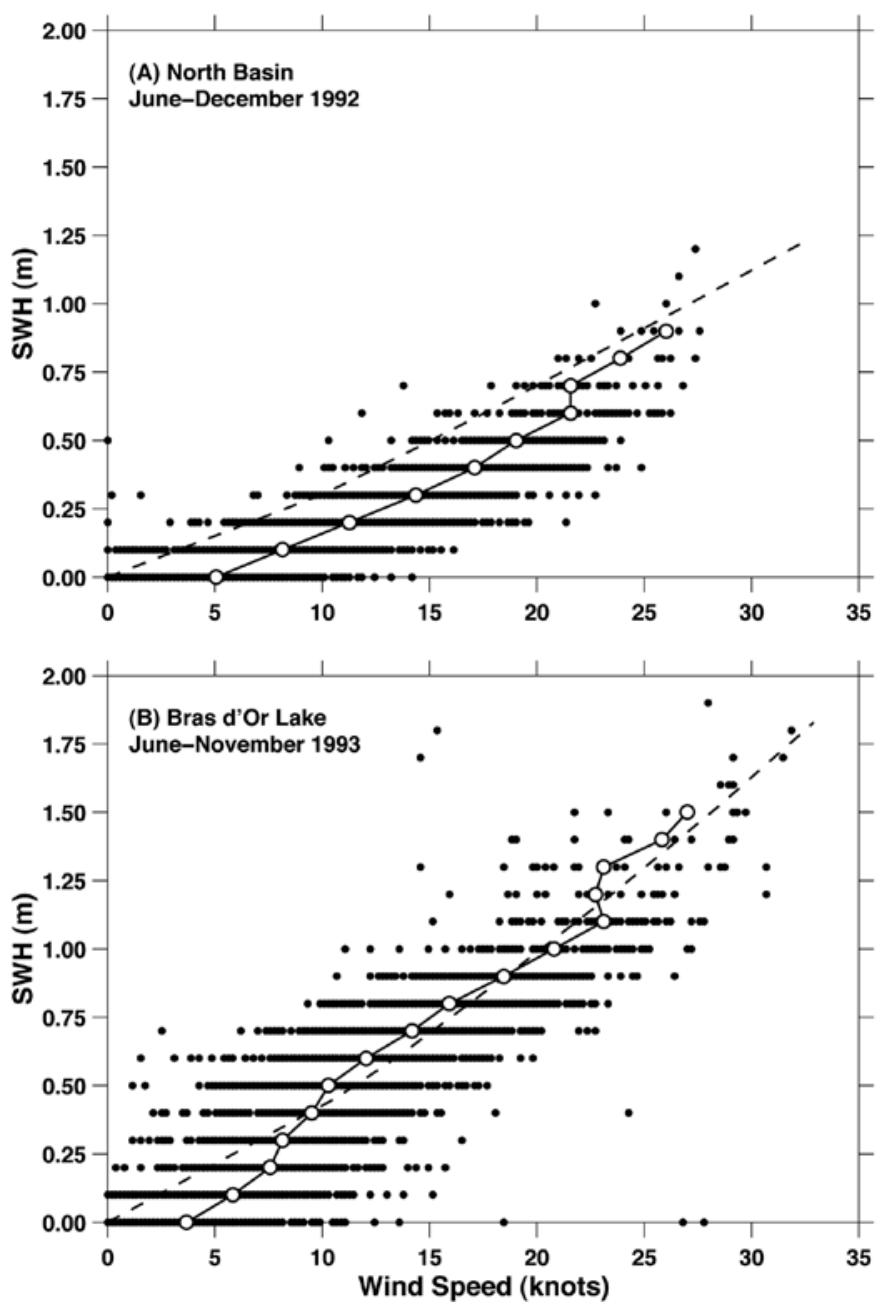

Fig 16 (A) Observed significant wave height (solid dot) for the North Basin as a function of wind speed. The medians of the observed values (solid line with open dots) and the predicted significant wave heights for a fetch of 6 nautical miles (broken line) are also shown. (B) Observed, median and predicted significant waves heights for a fetch of 15 nautical miles for the Bras d' Or Lake. 
weekly estimates for the percentage of the areas north and south of Barra Strait that are covered by ice (Fig 17A, B). The areas north of the Strait include St. Patrick's, St. Andrew's and the Great Bras d'Or Channels, and North Basin; East and West Bays, Bras d'Or Lake and Denys Basin comprise the areas south of the Strait. On average, ice cover begins to develop in January in both regions, although there are occasions when some cover occurs in December. The peak is reached in early March, with generally greater cover for a longer period in the region north of Barra Strait. Ice cover begins to decease rapidly in April and has generally disappeared by the first week of May.

Variations occur from year to year as noted above. One might expect that the air temperature plays a fundamental role in the extent of ice cover. In Fig 18, we show the December to February temperature anomaly at Baddeck plotted against the February to March ice cover. During a normal winter, the temperature anomaly at Baddeck is zero, i.e., it is equal to its long-term average December to February temperature. A warmer than normal winter has a positive anomaly, a colder than normal winter a negative anomaly. Average winters generally give rise to $70 \%$ ice cover on the Lakes. For colder than normal temperatures (negative anomalies), cover generally increases, reaching $100 \%$ for some years. Warmer than normal winters typically have less than $70 \%$ ice cover.
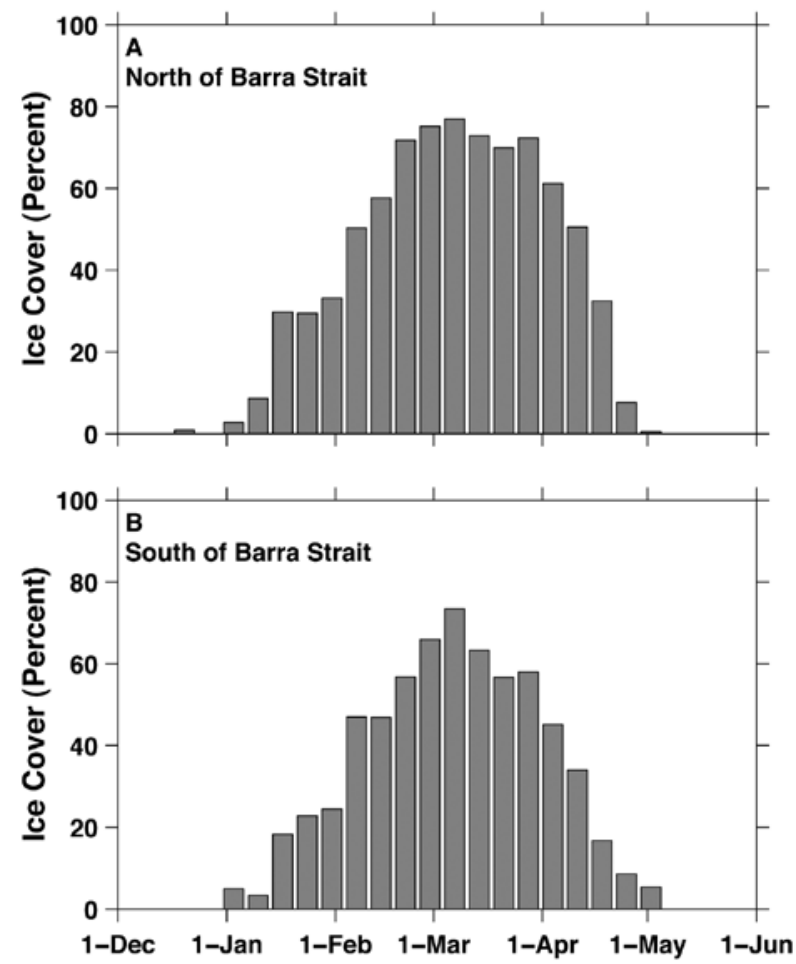

Fig 17 (A) Percentage of surface area north of Barra Strait covered by ice on average based on 30 years of data collected by the Atmospheric Environment Service.

(B) Percentage of surface area south of Barra Strait covered by ice. 


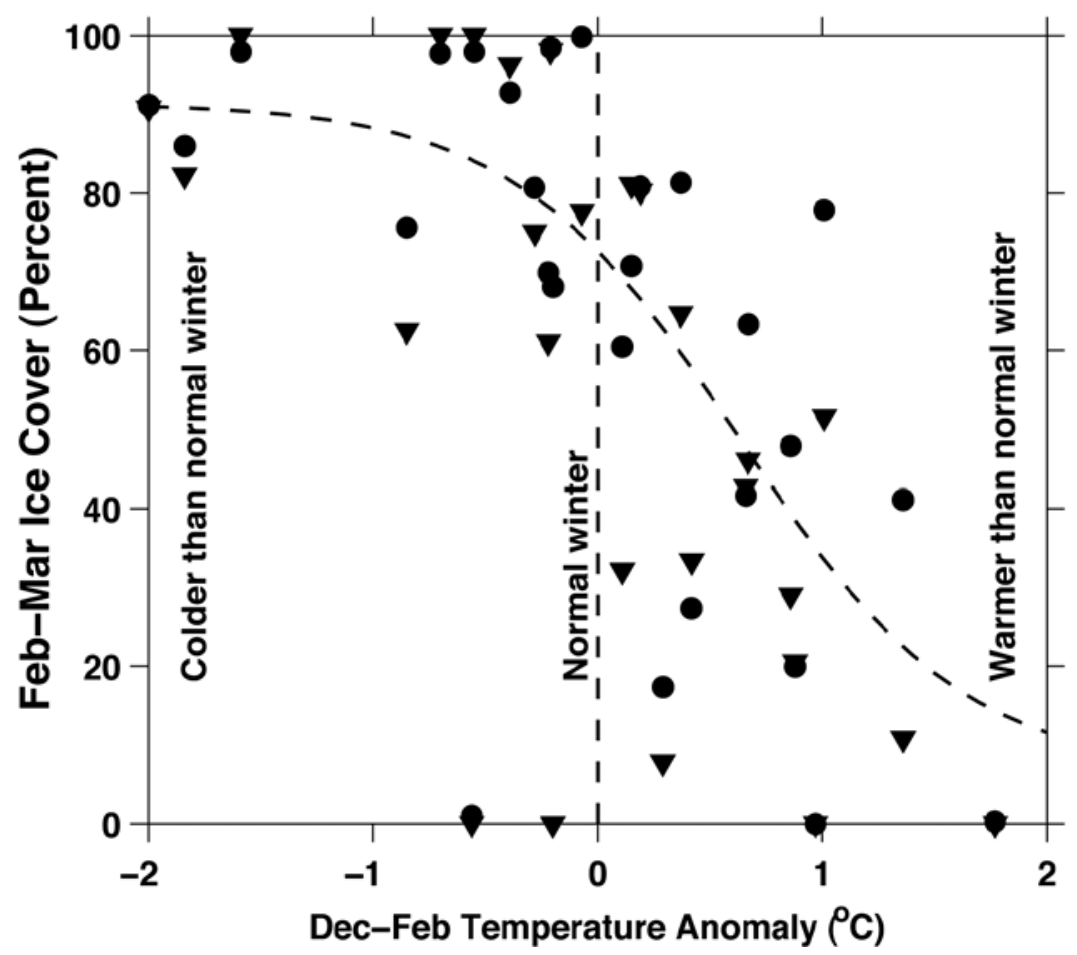

Fig 18 Winter (Feb-Mar) ice cover on the Bras d'Or Lakes (north of Barra Strait is represented by a triangle, south by a dot) compared to winter (Dec-Feb) air temperature anomaly at Baddeck. A temperature anomaly of $2(-2)$ corresponds to $2^{\circ} \mathrm{C}$ above (below) normal. An average winter has an anomaly of $0^{\circ} \mathrm{C}$. The broken line was fitted to the data to serve as a guide to the overall variation.

One factor that is missing from these data is ice thickness. During a colder than normal winter, ice cover can reach $100 \%$ but cannot exceed this value. However, for a very severe winter the ice thickness can significantly exceed the thickness during a winter that is only slightly colder than normal even though both may have $100 \%$ ice cover. The flight of the Silver Dart would not have been possible if the ice were only $1 \mathrm{~cm}$ thick.

\section{Conclusions}

From the analysis of archived data and the recent deployment of moorings we have learned a lot about the circulation, tides, mixing, temperature and salinity distributions, sea level, waves and ice cover in the Lakes. One of the major areas where knowledge has been lacking involves the winter circulation and convection that can occur because of the cooling of the near-surface waters. Comprehensive analysis of the data from the winter of 1998-1999 should help us understand the winter circulation. In the early fall of 2000, three moorings were placed in the Lakes, to explore the role that 
convection plays during the winter in mixing surface heat and salt to the deeper depths of the Lakes and in restoring oxygen levels to areas such as St. Andrew's Channel. These instruments will be recovered in the fall of 2001, redeployed for a final mooring period that will last until the spring of 2002. The data collected by this project will be valuable in our attempts to understand the workings of the Lakes during the winter. The analysis of these data will likely be completed in 2004.

The complicated patterns that we see in the current meter data collected in 19981999 will require a considerable modelling effort to arrive at an understanding. It is apparent from these data that the simpler models developed using the 1973-1974 data will not be adequate to explain the details of both the mean and the tidal circulation. However, these simpler models can be used to advantage to address multi-disciplinary issues. For example, the supply of nutrients through circulation and mixing could be estimated; the results could then be used to make estimates of primary production. The models could also be used as management tools to estimate the impact of pollutants or any water-borne variable on the Lakes. The combination of observations and modelling should continue to increase our understanding of the physical processes that affect the distribution of physical, biological and chemical variables in the Lakes.

\section{Acknowledgements}

We thank Dr. D. Wright and D. Greenberg for helpful reviews of this manuscript. Dr. Wright's comments led to improved discussions of the inverted barometer response and the role of mixing in the Lakes. We thank the reviewers also whose generous comments led to the addition of two figures (surface temperatures and salinities and mixed layer depth), corrections to a figure, and clarifications in the text.

\section{References}

Gurbutt, P. A., Petrie, B. and Jordan, F. 1993. The physical oceanography of the Bras d'Or Lakes: data analysis and modelling. Can. Tech. Rep. Hydrogr. Ocean Sci. 147, 61 pp.

Gurbutt, P. A. and Petrie, B. 1995. Circulation in the Bras d'Or Lakes. Estuar., Coastal and Shelf Sci. 41, 611-630.

Khandekar, M. 1989. Operational Analysis and Prediction of Ocean Waves. SpringerVerlag, New York, 214 pp.

Krauel, D. P. 1975. The physical oceanography of the Bras d'Or Lakes 1972-1974. Bedford Institute of Oceanography, Fisheries and Marine Science Service Tech. Rep. No. 570, 357 pp.

Krauel, D. P. 1975b. A summary of the physical oceanography of the Bras d'Or Lake system. In The Proceedings of the Bras d'Or Lakes Aquaculture Conference (McKay, G., ed.). College of Cape Breton Press, Sydney, Canada, pp. 29-43.

Parks Canada 2001. St. Peters Canal National Historic Site of Canada. http:// parkscanada.pch.gc.ca/parks/nova_scotia/st_peters_canal/st_peters_canal_e.html

Petrie, B. 1999. Sea level variability in the Bras d'Or Lakes. Atmos.-Ocean 37, 221-239.

Proudman, J. 1953. Dynamical Oceanography. Methuen and Co. Ltd., London, 409 pp.

The Yachtsman's Guide to the Bras d'Or Lakes 1987. Publ. by Spray Magazine, 1127

Barrington St., Halifax, N. S., B3H 2 P8.

(Received 1 March 2002) 